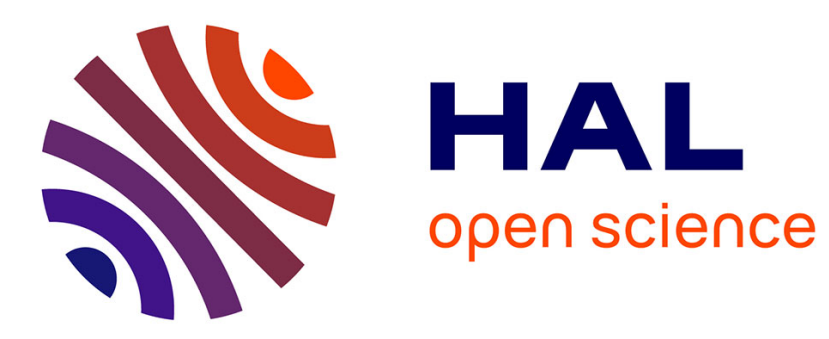

\title{
Control of metabolism by nutrient-regulated nuclear receptors acting in the brain.
}

\author{
Kadiombo Bantubungi, Janne Prawitt, Bart Staels
}

\section{To cite this version:}

Kadiombo Bantubungi, Janne Prawitt, Bart Staels. Control of metabolism by nutrient-regulated nuclear receptors acting in the brain.. Journal of Steroid Biochemistry and Molecular Biology, 2012, 130 (3-5), pp.126-37. 10.1016/j.jsbmb.2011.10.002 . inserm-00638195

\section{HAL Id: inserm-00638195 https://www.hal.inserm.fr/inserm-00638195}

Submitted on 4 Nov 2011

HAL is a multi-disciplinary open access archive for the deposit and dissemination of scientific research documents, whether they are published or not. The documents may come from teaching and research institutions in France or abroad, or from public or private research centers.
L'archive ouverte pluridisciplinaire HAL, est destinée au dépôt et à la diffusion de documents scientifiques de niveau recherche, publiés ou non, émanant des établissements d'enseignement et de recherche français ou étrangers, des laboratoires publics ou privés. 


\title{
Control of metabolism by nutrient-regulated nuclear receptors acting in the brain
}

\author{
Kadiombo Bantubungi ${ }^{1}$, Janne Prawitt ${ }^{1}$ and Bart Staels ${ }^{1}$ \\ 1 \\ Univ Lille Nord de France; INSERM UMR1011; UDSL; Institut Pasteur de Lille, Lille, \\ France
}

Address correspondence to:

Bart Staels; INSERM UMR1011, Institut Pasteur de Lille; 1 rue du Professeur Calmette, BP245; 59019 Lille, France; Phone: +33-3-20877388; Fax: +33-3-20877360; Email:

Bart.Staels@pasteur-lille.fr

\begin{abstract}
Today, we are witnessing a rising incidence of obesity worldwide. This increase is due to a sedentary life style, an increased caloric intake and a decrease in physical activity. Obesity contributes to the appearance of type 2 diabetes, dyslipidemia and cardiovascular complications due to atherosclerosis, and nephropathy. Therefore, the development of new therapeutic strategies may become a necessity. Given the metabolism controlling properties of nuclear receptors in peripheral organs (such as liver, adipose tissues, pancreas) and their implication in various processes underlying metabolic diseases, they constitute interesting therapeutic targets for obesity, dyslipidemia, cardiovascular disease and type 2 diabetes. The recent identification of the central nervous system as a player in the control of peripheral metabolism opens new avenues to our understanding of the pathophysiology of obesity and type 2 diabetes and potential novel ways to treat these diseases. While the metabolic functions of nuclear receptors in peripheral organs have been extensively investigated, little is known about their functions in the brain, in particular with respect to brain control of energy homeostasis. This review provides an overview of the relationships between nuclear receptors in the brain, mainly at the hypothalamic level, and the central regulation of energy homeostasis. In this context, we will particularly focus on the role of PPAR $\alpha, \operatorname{PPAR} \gamma, \mathrm{LXR}$ and Rev-erbo.
\end{abstract}

Keywords: Nuclear receptors; brain; energy homeostasis 


\section{Abbreviations}

2DG: 2-deoxy-D-glucose

ABCA1: ATP binding cassette transporter sufamily A1

ABCG1: ATP binding cassette transporter sufamily G1

ABCG5: ATP binding cassette transporter sufamily G5

ABCG8: ATP binding cassette transporter sufamily G8

ACC: acetyl-CoA carboxylase

AgRP: agouti gene-related protein

ANS: autonomic nervous system

AMPK: AMP activated protein kinase

ApoE: apolipoprotein E

ARC: arcuate nucleus

BBB: blood-brain barrier

Bmal1: Brain and muscle ARNt like protein

CART: cocaine- and amphetamine regulated transcript

CCK: cholecystokinin

Clock: Circadian locomotor output cycle kaput

CNS: central nervous system

CNTF: ciliary neurotrophic factor

CPT1: carnitine palmitoyltransferase-1

$\mathrm{CRH}$ : corticotropin-releasing hormone

Cry: Cryptochrome

DBD: DNA-binding domain

DCV: dorsal vagal complex

DMH: dorsomedial hypothalamus

DMV: dorsal motor of the vagus nerve

FAS: fatty acid synthase

FATP: FA transporters type 1

GE: glucose-excited

GI: glucose inhibited

GLP1: glucagon like peptide-1

GLUT2: glucose transporter 2

GLUT4: glucose transporter 4

GK: glucokinase

LBD: ligand-binding domain

LCFA long-chain fatty acid

LHA: lateral hypothalamic area

LPL: lipoprotein lipase

LXR: liver $X$ receptor

MC3R: melanocortin-3 receptor

MC4R: melanocortin-4 receptor

MCD: malonyl-CoA decarboxylase

$\mathrm{MCH}$ : melanin-concentrating hormone

MnPO: median preoptic nucleus

MPOA: median preoptic area

$\alpha-, \beta-, \gamma-\mathrm{MSH}$ : Melanocyte stimulating hormones alpha, beta, gamma

MTII: melanotan II

NPY: neuropeptide Y

NR: nuclear receptor 
NTS: nucleus of the solitary tract

PPAR: peroxisome proliferator-activated receptor

PEPCK: phosphoenolpyruvate carboxylase

Per: Period

PI3K: phosphatidylinositol 3'-kinase

PVN: paraventricular nucleus

RXR: Retinoid X Receptor

SCN: suprachiasmatic nucleus

sPVZ: the subparaventricular nucleus

T2D: type 2 diabetes

TG: triglycerides

TRH: thyrotrophin-releasing hormone

TZD: thiazolidinediones

VHM: ventromedial hypothalamus

VLPO: ventrolateral preoptic nucleus 


\section{Introduction to nuclear receptors}

The superfamily of nuclear receptors (NR) is formed by 48 members in the human genome. NRs are transcription factors generally activated through binding of ligands, often small lipophilic molecules including fatty acids, hormones, bile acids and oxysterols. However, some NRs have no identified ligands and remain orphans. NRs can be classified either according to phylogenetic parameters [1] or by their dimerization, DNA and ligand binding properties, which gives rise to four separate classes [2]. Several NR subfamilies comprise different receptor subtypes each coded by individual genes (e.g. Retinoid X Receptor $(\mathrm{RXR}) \alpha, \mathrm{RXR} \beta, \mathrm{RXR} \gamma$ ) which in addition may produce different receptor isoforms by alternative splicing (e.g. $\operatorname{RXR} \alpha 1, \mathrm{RXR} \alpha 2)$ [2-3].

NRs are composed of common structural domains which include a ligand-independent activation domain (AF-1), a zinc finger DNA-binding domain (DBD), a hinge domain allowing conformational changes, a ligand-binding domain (LBD) and ligand-dependent activation domain (AF-2), as well as a C-terminal domain. Some NRs can bind DNA and activate transcription of their target genes as monomers, but the majority are active as homodimers or heterodimers with RXR [2]. DNA-bound receptors regulate transcription in different ways depending on their ligand status. In general, unliganded or antagonist-bound receptors are transcriptionnally inactive or they promote transcriptional repression. Conversely, agonist-bound receptors promote transcriptional activation. The specificity of the complexes formed between the NR and corepressors or coactivators seems to be defined by the cell type, the conformational change induced by the ligand and the sequence of the DNAbinding element. This level of complexity enables fine-tuning of the physiological response and explains the differences in gene expression regulation depending on the type of ligand activating a given NR.

NRs play fundamental roles in various biological processes such as embryonic development, cell differentiation, cell death or metabolism. Therefore, NR dysfunction has important implications for the organism and may cause serious disease. NRs are involved in various processes underlying many human metabolic diseases such as type 2 diabetes (T2D), dyslipidemia and cardiovascular diseases. The development of specific ligands may thus be of interest to combat these diseases.

\section{Metabolic functions of NRs in peripheral organs}


Hormones and metabolites such as fatty acids, bile acids or oxysterols are natural ligands of specific NRs. Thus, NRs act as metabolic sensors, enabling the organism to quickly adapt to environmental changes. Particularly, within metabolically active organs, NRs are master regulators of genes involved in metabolic control, integrating homeostatic control of energy and glucose, lipid and bile acid metabolism. In this section, we provide a brief overview of the metabolic function of a number of NRs via their actions in the periphery.

\subsection{PPAR $\alpha$}

PPAR $\alpha$ is predominantly expressed in the liver, heart, brown adipose tissue, kidney and intestine where it regulates energy homeostasis [4]. The identification of PPAR $\alpha$ target genes revealed that this NR regulates fatty acid and triglyceride catabolism (fatty acid uptake, peroxisomal oxidation, lipoprotein metabolism)[5-10]. PPAR $\alpha$-deficient mice develop hypoglycemia, hypoketonemia and fatty liver during fasting [8]. The increased fatty acid oxidation in response to PPAR $\alpha$ activation with synthetic agonists decreases circulating triglyceride levels and reduces lipid stores in liver, muscle, and adipose tissue [11], associated with improved insulin sensitivity [12-13]. PPAR $\alpha$ stimulation is thus of interest for the treatment of dyslipidemia and fibrates, which are synthetic agonists, are clinically used in this context [14-16].

\subsection{PPAR $\gamma$}

PPAR $\gamma$ is highly expressed in adipose tissue (see review [17]). PPAR $\gamma$ regulates adipogenesis by promoting the expression of specific adipocyte markers such as adipocyte lipid binding protein (aP2), phosphoenolpyruvate carboxylase (PEPCK) or lipoprotein lipase (LPL) [18-21]. Moreover, PPAR $\gamma$ plays a key role in fatty acid uptake and storage followed by esterification into triglycerides (TG) [18-19,22-23]. Furthermore, PPAR $\gamma$ controls glucose homeostasis by improving insulin sensitivity in adipose tissue, skeletal muscle, liver and pancreas [24-26]. Therefore, synthetic PPAR $\gamma$ agonists (thiazolidinediones (TZD), glitazones) are clinically used as insulin sensitizers in the treatment of patients with T2D. However, these treatments can also lead to side effects as TZD induce weight gain, bone fractures and possibly heart insufficiency in patients and rodent models [27-28].

\subsection{LXRs}


Two LXR isotypes, LXR $\alpha$ and LXR $\beta$, have been identified. LXR $\alpha$ is highly expressed in liver and at lower levels in the intestine and adipose tissue. While LXR $\beta$ is ubiquitously expressed [29], it is particularly abundant in brain with levels 2 to 5 fold higher than in the liver [30]. LXRs, which are important regulators of cholesterol, lipid and glucose metabolism [31-35], are activated by oxysterols, oxidized derivatives of cholesterol including hydroxycholesterols [36-37], as well as by cholesterol precursor sterols [38-39]. In addition to shared functions, LXR $\alpha$ and LXR $\beta$ also exert different regulatory functions [32,35,40-42]. While a number of genes are regulated by both subtypes, several genes in adipose tissue are regulated selectively by either $\operatorname{LXR} \alpha$ or $\operatorname{LXR} \beta$ [40]. In liver, LXR $\alpha$ appears as the more important subtype involved in the regulation of cholesterol metabolism and lipogenesis [40][32][42][35]. Although LXR $\alpha$-deficient mice accumulate toxic levels of hepatic cholesterol and develop hypercholesterolemia in response to dietary cholesterol, LXR $\beta$ deficient mice are resistant to cholesterol-induced fatty liver [32, 35]. When cellular oxysterols accumulate, activated LXR induces the transcription of genes involved in cholesterol efflux and bile acid metabolism/excretion (e.g. ABCA1, ABCG1, ABCG5, ABCG8, ApoE) thus protecting the cell from cholesterol overload. Thus, LXRs are considered as cholesterol sensors playing a critical role in the control of lipid and cholesterol metabolism (see review [43]).

\subsection{Rev-erb $\alpha$}

Rev-erb $\alpha$ is a NR expressed in a circadian manner in liver, intestine, muscle, pancreas and adipose tissues [44-48]. Indeed, Rev-erb $\alpha$ is itself a clock gene participating in the control of the circadian rhythm in peripheral organs and plays an important role in synchronization processes. Heme is the only known natural ligand of Rev-erba [49], which regulates lipid and glucose metabolism [44,50-51], bile acid synthesis [52] and adipogenesis [53-54]. Specifically, Rev-erb $\alpha$ modulates both systemic and hepatic lipid metabolism by repressing the expression of elovl3, a gene encoding a very long chain fatty acid elongase, and liver apolipoprotein C-III, a constituent of very low density lipoproteins acting as LPL inhibitor [50]. Rev-erba may also affect muscle lipid metabolism and exercise-induced energy mobilization [55]. In addition, Lazar et al.[49] have demonstrated that Rev-erbo represses expression of gluconeogenic genes such as PEPCK, thereby suggesting a role for Rev-erb $\alpha$ in 
glucose metabolism and in the fasting/refeeding transition response. Rev-erb $\alpha$ also modulates bile acid synthesis and Rev-erb $\alpha$-deficient mice display altered circadian expression of genes involved in bile acid metabolism [52]. Together, these data strongly argue for a role of Reverb $\alpha$ in the circadian alignment of metabolic processes with both central and peripheral circadian outputs.

\section{Central control of metabolism}

A growing body of evidence demonstrates that the brain plays a crucial role in the regulation and coordination of whole-body energy homeostasis [56-58]. The brain constantly collects information about the energy status of the periphery to promote appropriate adaptive responses. Afferent signals that convey information about body fuel stores from the periphery to the central nervous system (CNS) are subdivided into several categories: (1) adiposity signals such as insulin and leptin, which are produced in proportion to nutritional status and fat mass; (2) nutrient-related signals, such as glucose, free fatty acids or amino acids; (3) satiety signals generated after the ingestion and absorption of food by the gastrointestinal tract; (4) secreted molecules like cholecystokinin (CCK) and glucagon like peptide-1 (GLP-1) [59-63]. Noteworthy, all these signals are integrated directly or indirectly by specific hypothalamic and autonomic networks described in section 3.2 of this review (Figure 1).

\subsection{Responses induced by adiposity and nutrient-related signals}

Within the hypothalamus (in particular the arcuate nucleus (ARC)), subsets of neurons are responsive to adiposity (insulin, leptin) or nutrient-related signals (glucose, fatty acids) which evoke a set of neurochemical and neurophysiological responses, thereby regulating energy homeostasis.

\subsubsection{Adiposity signal responses}

The adiposity signals, leptin and insulin, respectively synthesized by adipose tissue and the pancreas, circulate in proportion to body fat [62, 64-67]. They inform the CNS that adipose stores increase and that the organism is in a positive state of energy balance. Adiposity signal integration is mediated by the well-characterized melanocortin system [68]. This complex 
signaling network comprises (1) neurons in the ARC expressing either the anorexigen proopiomelanocortin (POMC) and the cocaine- and amphetamine regulated transcript (CART) or both the orexigens neuropeptide $\mathrm{Y}$ and agouti gene-related protein (NPY/AgRP), (2) brain stem POMC neurons situated in the commissural nucleus of the solitary tract (NTS) and (3) downstream targets of POMC and AgRP neurons expressing the melanocortin-3 (MC3R) and melanocortin-4 (MC4R) receptor (Figure 1). Of the five cloned melanocortin receptors, MC3R and MC4R have been identified as important downstream effectors regulating energy homeostasis. So far, MC4R seems more involved in energy homeostasis. Melanocyte stimulating hormones $(\alpha-, \beta-, \gamma-\mathrm{MSH})$ released from POMC neurons activate MCRs, while AgRP produced by NPY/AgRP neurons is an endogenous antagonist.

Both leptin and insulin penetrate into the brain either through the blood-brain barrier (BBB) by a saturable receptor-mediated transport or at the level of the median eminence of the hypothalamus, one of the seven so-called circumventricular organs characterized by a relatively porous blood-brain interface with the ability to extract nutrients and hormones from the circulation. Leptin and insulin act through their respective receptors present in CNS regions involved in the regulation of food intake and body weight, especially the ARC in the mediobasal hypothalamus. Leptin and insulin receptors are expressed on both anorexigenic POMC/CART and orexigenic NPY/AgRP neurons (Figure 2A and 2B). Leptin binding activates POMC/CART neurons causing the release of $\alpha-\mathrm{MSH}$, which via the melanocortin system decreases food intake and increases energy expenditure. By contrast, NPY/AgRP neurons are inhibited by leptin binding, decreasing the NPY and AgRP release, the latter of which results in an increased melanocortinergic tone [69-73]. Like leptin, insulin upregulates arcuate POMC and decreases AgRP gene expression [74]. Both the leptin and the insulin signal transduction pathways converge on phosphatidylinositol 3'-kinase (PI3K), regulating cell excitability in POMC/CART and NPY/AgRP neurons via ATP-sensitive potassium $\left(\mathrm{K}_{\mathrm{ATP}}\right)$ channels [75]. However, while insulin hyperpolarizes and thereby silences both POMC and AgRP neurons, leptin hyperpolarizes AgRP but depolarizes POMC neurons thus increasing their firing rate $[70,74,76]$. The precise mechanisms underlying the differential effects of leptin and insulin on electrophysiological activity through PI3K are still to be determined.

\subsubsection{Nutrient-related signal responses}


Like adiposity signals, nutrient-derived compounds (glucose, fatty acids) act as molecules signaling the whole body nutritional status and informing the brain of energy reserves. The cellular and molecular mechanisms involved in nutrient detection by hypothalamic neurons are related to intracellular nutrient metabolism (see review [56,58,77-79]).

\subsubsection{Glucose sensing}

The importance of central glucose sensing in the regulation of feeding behavior was proposed more than 50 years ago [80]. By now, food intake, energy expenditure and hepatic glucose production are known to be regulated by central glucose sensing (see review:[81]). Similar as in pancreatic $\beta$-cells, glucose enters the neurons via the glucose transporter (GLUT2), is phosphorylated by glucokinase (GK) and processed via the TCA cycle subsequently increasing intracellular ATP levels which inhibit $\mathrm{K}_{\text {ATP }}$ channels. The subsequently modified calcium flux results in either cell depolarization or hyperpolarization leading to an increase or a decrease in firing activity, respectively [56, 82]. According to the neuron's reaction towards extracellular glucose concentrations, glucose-excited (GE) and glucose-inhibited (GI) neurons are distinguished (Figure 3). Both types are highly enriched in regions of the hypothalamus such as the ARC (see section 3.2). After an elevation of glucose concentrations, anorexigenic POMC/CART neurons depolarize in the ARC, increasing their firing rate (acting as GE neurons), whereas orexigenic AgRP neurons are inhibited by glucose [83-84]. The importance of glucose sensing within hypothalamic nuclei and the brain stem for the control of food intake, energy expenditure and hepatic glucose production are supported by several studies. Thus, intra-hypothalamic glucose infusion decreases food intake and body weight [85-87], while 2-deoxy-D-glucose (2DG), a glucose analogue, which cannot be metabolized, increases food intake [88-89]. Noteworthy, the brain stem seems to be the primary site for the detection of glucose deprivation, since the direct injection of 5thioglucose, a 2DG analogue, stimulates food intake [88,90]. Furthermore, the destruction of hypothalamic projections from the brain stem to the ARC or paraventricular nucleus (PVN) suppresses the effect of 2DG on feeding behavior [91]. In addition, proteins implicated in glucose metabolism and sensing modulate feeding patterns or hepatic glucose production. GLUT2 inactivation by anti-sense oligonucleotides or targeted gene disruption altered food intake. In fasted Glut2-deficient mice, intracerebroventricular glucose injection failed to reduce orexigenic NPY and to induce anorexigenic POMC expression [92]. These data indicate that GLUT2 is required for the physiological control of feeding by glucose. Further, 
glucose regulation of firing activity was suppressed in mice lacking AMPKa2, an AMP sensor, in either POMC (POMCa2KO) or AgRP/NPY (AgRPa2KO) neurons, indicating a role for AMPK in glucose sensing [93].

\subsubsection{Fatty acid sensing}

Several studies have shown that central administration of oleic acid reduces food intake, body weight, energy homeostasis and hepatic glucose production [81,94-98]. The intracellular metabolization of fatty acids (FA) seems crucial for the electrophysiological activity of hypothalamic neurons and thereby for their role in energy homeostasis.

The role of free FA as signaling molecules in the brain has only recently been studied, mainly since lipids were thought not to cross the BBB. Indeed, in a series of studies conducted in 1940, Sperry et al. [99] detected no significant concentrations of dietary FA in rat brain concluding that brain lipids derive from endogenous synthesis. However, by now it is clear that in addition to intracerebral synthesis, extracerebral sources (dietary fat or adipocyte lipolysis) contribute to the pool of brain lipids. FA have recently been shown to permeate the BBB. However, the implicated mechanisms are still poorly understood. According to some reports, plasma long-chain FA (LCFA) which circulate bound to albumin cross the BBB mostly by simple diffusion of the unbound form [100]. In general, the entry rate of FA into the brain is relative to the plasma concentration [77]. Other studies argue for a mechanism of facilitated FA transport across the BBB [101], supported by the existence of FA transporters (FATP) type 1 in the mouse and type 4 in the human CNS [102].

After crossing the BBB, LCFA are taken up by neurons and glial cells, esterified to LCFACoA and either enter lipid (particularly phospholipid) biosynthesis or, to a much lesser extent, $\beta$-oxidation [77](Figure 4), depending on the type of LCFA. Rapoport et al.[103] showed that $50 \%$ of imported palmitate is oxidized in the brain, while $80 \%$ of arachidonate is incorporated into phospholipids. By now the presence of key players of lipid biosynthesis (such as acetylCoA carboxylase (ACC), fatty acid synthase (FAS), malonyl-CoA decarboxylase (MCD)) and $\beta$-oxidation (such as carnitine palmitoyltransferase-1 (CPT1)) in the hypothalamus (particularly in ARC, ventromedial hypothalamus (VMH) and dorsomedial hypothalamus (DMH)) are well established [104-106]. In analogy to mechanisms described in peripheral tissues, such as skeletal muscle, malonyl-CoA has been proposed as the actual FA-derived energy sensor in brain. Malonyl-CoA is produced by ACC from acetyl-CoA, which derives from either glucose or FA oxidation, and is thus located at the intersection of glucose and 
lipid metabolism. Malonyl-CoA potently inhibits CPT1 activity and consequently decreases the entry of FA into the mitochondria for $\beta$-oxidation. A growing body of evidence suggests that malonyl-CoA is a powerful satietogenic signal. Pharmacological and genetic approaches have shown that the alteration of FAS expression and activity in the brain modulates feeding. Central administration of C75, a FAS inhibitor, suppressed food intake and induced profound weight loss $[97,107,108]$ by decreasing the expression of orexigenic (AgRP, NPY) and inducing the expression of anorexigenic (CART, POMC) neuropeptides in the ARC [107110]. This anorectic effect of C75 required the accumulation of malonyl-CoA in the hypothalamus, which may be sensed as a signal of nutrient abundance by critical neurons regulating food intake [109,111-112]. Furthermore, the modulation of hypothalamic FA metabolism was shown to be part of the adaptive changes observed during the physiological regulation of feeding. During fasting, hypothalamic AMP-activated protein kinase (AMPK), which phosphorylates and subsequently inactivates ACC, is activated, thus inhibiting hypothalamic ACC and FAS activity, whereas refeeding induces opposite changes [96,110111,96]. In line with this observation, orexigenic signals, such as cannabinoids, glucocorticoids, adiponectin, ghrelin and agouti-related protein (AgRP), activate AMPK and inhibit ACC and FAS [114-118]. In contrast, anorexigenic hormones, such as leptin, insulin, glucagon-like peptide-1 (GLP-1), ciliary neurotrophic factor (CNTF) and melanocortin receptors agonists, such as melanotan II (MTII), inhibit hypothalamic AMPK activating ACC and/or FAS [113,119-121]. Thus, the contribution of FA metabolism to the control of food intake is established. However, the molecular mechanisms that link FA sensing to the electrophysiological function of hypothalamic neurons remain elusive.

\subsection{Circuits involved in energy homeostasis}

The control of energy homeostasis by the CNS in response to adiposity, nutrient and satiety signals is achieved by closely interconnected neuroendocrine and autonomic pathways. The involved brain regions are localized in the hypothalamus and the brain stem and constitute specific neurocircuits which continuously monitor afferent signals reflecting the organism's energy status. These processes are under the control of three brain networks: (1) a hypothalamic network of energy centers controlling energy homeostasis, (2) a hypothalamic network of circadian centers controlling the central circadian rhythm and (3) the brain stem which connects the autonomic nervous system (ANS) and the hypothalamic networks (Figure 1). 


\subsubsection{The energy network}

The energy network is composed of the arcuate nucleus of the hypothalamus (ARC), the lateral hypothalamic area (LHA), the paraventricular nucleus (PVN), the ventromedial hypothalamus (VMH) and the dorsomedial hypothalamus (DMH).

The ARC is considered as the primary integrative center of the hypothalamus, ideally situated in the vicinity of the third ventricle and the median eminence. The major integration process of the ARC is conducted by the melanocortin system involved in the sensing of adiposity and nutrient-related signals [63,122](Schwartz et al., 2000; Spiegelman et al., 2001). POMC and NPY/AgRP neurons of the ARC project into other hypothalamic nuclei such as the PVN and the LHA, but also into extra-hypothalamic regions. Noteworthy, the nucleus tractus solitarus (NTS) and the dorsal motor of the vagus nerve (DMV) also receive projections from POMC neurons in the ARC [68].

The PVN is an important hypothalamic nucleus for the integration of autonomic and neuroendocrine information thereby contributing to the regulation of fluid balance and cardiovascular homeostasis [123-124]. Its role in the regulation of pituitary hormone secretion via the release of neuroendocrine factors such as oxytocin, thyrotrophin-releasing hormone (TRH) or corticotropin-releasing hormone (CRH) is well characterized [125], but less is known about the impact of melanocortin signals from the PVN on the regulation of energy balance. Nevertheless, several studies demonstrate that (1) the PVN is one of the regions most densely innervated by POMC and NPY/AgRP neurons which further contains MC4R expressing neurons, (2) neurons within the PVN are able to detect and integrate melanocortin signals [126], (3) the PVN innervates the NTS which integrates gut-derived satiety signals [56]. Noteworthy, the PVN also contains GE and GI neurons participating in glucose sensing. These characteristics emphasize the importance of the PVN within the melanocortin system and raise the interest in further studies that elucidate its role in the regulation of energy metabolism.

The VMH and DMH are additional hypothalamic regions critical for nutrient-sensing. The $\mathrm{DMH}$ is a particular hypothalamic nucleus because it is implicated in the integration of both circadian rhythm (see section 3.2.2) and energy homeostasis via the melanocortin system [127-128]. The VMH receives input from the ARC and subsequently projects it into different extra- and hypothalamic nuclei. However, the neurochemical identities of VMH nutrientsensing neurons are not well established. 
Last, the LHA contains two distinct groups of neurons: (1) melanin-concentrating hormone $(\mathrm{MCH})$ containing neurons, (2) neurons containing orexins and (3) glucose sensitive neurons. These neurons have been suggested to play a significant role in regulating energy balance [129] at least in part through interactions with the melanocortin system [130-135] and through their projection into the NTS [136]. In addition to their ability to detect nutrient availability, LHA neurons receive and integrate sensory inputs and reward/motivation-related information, and widely project into several areas in the hindbrain, cortex, limbic system, thalamus and spinal cord, enabling them to activate both behavioral and autonomic output systems [137]. Finally, in addition to its role in feeding behavior, the LHA is known to be implicated in the regulation of wakefulness [138].

\subsubsection{The circadian network}

The neuronal centers controlling the central circadian rhythm are closely interconnected with the energy network and comprise the suprachiasmatic nucleus (SCN), the subparaventricular nucleus (sPVZ), the DMH, the ventrolateral preoptic nucleus (VLPO), the median preoptic nucleus (MnPO) and the median preoptic area (MPOA) (Figure 1). The master circadian pacemaker has been localized in the SCN, a retinorecipient cluster of +/160,000 neurons bilaterally distributed at the base of the third ventricle in the anterior hypothalamus. The SCN integrates information mainly from light, but also from scheduled food availability and synchronizes the whole body physiology to the day/night alternation. The activation of the SCN drives clocks located in other brain regions and peripheral organs [139]. Importantly, the SCN projects into the $\mathrm{DMH}$, a gateway structure between the circadian and the energy center, which in turn projects particularly into the LHA. The latter is involved in the control of wakefulness and feeding through neuroendocrine inputs from the ARC where both adiposity and nutrient-related signals are integrated. Of note, both circadian and energy centers are closely connected at both neuroanatomical (projections) and neuroendocrine levels (Figure 1). At the molecular level, the SCN clock is composed of different clock genes: Period (Per), Cryptochrome (Cry), Circadian locomotor output cycle kaput (Clock) and Brain and muscle ARNt like protein 1 (Bmall). In mammals, clock and Bmal1 form the positive limb and activate the transcription of various target genes including Per and Cry, which in turn repress Clock/Bmall-mediated gene transactivation, thereby forming a negative feedback cycle shutting down their own transcription. This allows a new cycle to start. Emerging evidence demonstrates that genes of the clock machinery directly 
influence energy homeostasis and that mutations in clock genes lead to metabolic disorders. Thus, Clock mutant mice are hyperphagic, become obese and develop hyperlipidemia and hyperglycemia [140]. Another report shows altered circadian oscillations in plasma glucose and triglyceride levels and glucose intolerance in Clock $^{\text {mut }}$ Bmall $^{-/-}$mice [141]. Finally, a recent study indicates that genetic variations of clock may play a role in the development of the metabolic syndrome in humans [142].

\subsubsection{The autonomic nervous system}

The ANS is involved in the control of energy homeostasis. The ANS represents an important neuronal network connecting the CNS with peripheral metabolic processes complementary to adiposity signals and nutrient sensing. Kreier et al. (2006)[143] demonstrated that the liver, the pancreas, and visceral adipose tissue share a common and specific neuronal connection with the CNS. The CNS neuronal circuits which are responsible for sensing peripheral signals relevant for energy balance regulation (energy and circadian networks, described in section 3.2.1 and 3.2.2) are closely connected with neuronal projections to and from metabolically important peripheral organs [144-145]. The PVN links the energy balance regulatory system to the ANS [124,146]. More precisely, the PVN is the key central structure involved in integrating afferent autonomic information, on the one hand, and coordinating neuroendocrine and autonomic motor outputs, on the other hand. The preautonomic neurons in the PVN receive parasympathetic-mediated neuronal information from the brain stem, in particular from the NTS, as well as from energy network neurons. The NTS is included with the dorsal motor nucleus of the vagus nerve (DMV) in the brain stem dorsal vagal complex (DVC). The DVC plays a critical role in the autonomic parasympathetic control of energy homeostasis through the activation of the vagus nerve. Neurons of the vagus nerve control gastrointestinal motility as well as the function of liver, pancreas and other organs whose functions are significantly altered in diabetes. Noteworthy, the NTS can also integrate adiposity signals like leptin or insulin from the periphery, partly transmitted by the ARC [147], as well as nutrient-related signals such as glucose. Indeed, the brain stem contains highly sensitive GE and GI neurons in the DMV and NTS, which may project into and hence regulate the activity of hypothalamic neurons that are part of the hypothalamic energy network. Finally, a neuroanatomical link between the SCN and peripheral tissues such as adipose tissue [148] and the liver [149] has been demonstrated, indicating that the ANS directly transfers circadian information to its cellular targets in peripheral organs [150]. 


\section{What about NRs in the central control of metabolism?}

Recent studies have demonstrated that NRs are expressed within different brain regions [151-153]. Despite the presence of most NRs in the CNS, in particular in the hypothalamic energy and circadian networks as well as in the brain stem, little is known about their role in the central control of energy homeostasis. In the following section, we will focus on the PPARs, LXRs and Rev-erba. Hypothalamic functions of glucocorticoid, thyroid and estrogen receptors have been described elsewhere (see review: [154-156]).

\subsection{PPAR $\alpha$ and PPAR $\gamma$}

Whereas the role of all PPAR isotypes in brain development, neuro-immunology and CNS disorders such as Alzheimer's disease or multiple sclerosis, has been intensively studied [157], little is known about their involvement in the central control of energy homeostasis. In the brain, PPAR $\alpha$ expression has been reported in neurons as well as astrocytes [158]. Gofflot et al. (2007)[153] further detected PPAR $\alpha$ expression by quantitative PCR in various brain regions such as the cortex, brain stem and hypothalamus. At present, only two studies have examined the possible role of PPAR $\alpha$ in the central control of energy homeostasis. Knauf et al. (2006)[159] showed that in the absence of PPAR $\alpha$, whole-body and white adipose tissue glucose utilization, GLUT4 expression, fat mass, and insulin sensitivity were increased. Adenovirus-mediated PPAR $\alpha$ re-expression in the liver did not reverse the phenotype demonstrating that the lack of hepatic PPAR $\alpha$ did not underlie this phenotype. Conversely, intracerebroventricular (icv) administration of the PPAR $\alpha$ activator Wy14643 reduced wholebody and adipose tissue glucose utilization as well as whole-body glucose turnover in wildtype but not PPAR $\alpha$-deficient mice. Interestingly, another study has suggested a crosstalk between PPAR $\alpha$ signaling and FA metabolism in the central control of energy homeostasis [160]. The conditional inactivation of FAS expression in the hypothalamus led to lean, hypophagic mice that exhibit an increased physical activity. FAS deletion was associated with an accumulation of malonyl-CoA and an impaired PPAR $\alpha$ signaling, which the authors suggest to be directly responsible for the observed decrease in food intake. Intrahypothalamic and icv administration of Wy14643 restored PPAR $\alpha$ signaling in mice with hypothalamic FAS deletion, reflected by the induction of hypothalamic CPT1 and MCD expression, leading to a decrease in malonyl-CoA content and an elevation of food intake. Altogether, these data 
suggest that peripheral glucose homeostasis is under the control of PPAR $\alpha$ in the brain and that hypothalamic FAS is crucial for the regulation of feeding behavior by activating PPAR $\alpha$. However, it appears paradoxal that FAS, an enzyme activated by feeding, regulates PPAR $\alpha$, a NR involved in the response to fasting [160]. Hence, the contribution of PPAR $\alpha$ to the central control of energy metabolism is far from clear, particularly the impact of PPAR $\alpha$ on the nutrient-sensing process or the melanocortin system remains so far unknown.

Similar as for PPAR $\alpha$, there is little information on the role of central PPAR $\gamma$ in the control of energy homeostasis. While Gofflot et al. (2004) [153] did not detect PPAR $\gamma$ in mouse brain by in situ hybridization and only at weak levels by quantitative PCR (in cortex, brain stem and hypothalamus), other studies demonstrated PPAR $\gamma$ immunoreactivity in rat hypothalamus, especially in key neuronal subsets regulating energy homeostasis [151]. A third study reported neurons as the primary source of PPAR $\gamma$ in mouse hypothalamus, since the neuron-specific deletion of PPAR $\gamma$ using the Cre-lox strategy resulted in a decrease of PPAR $\gamma$ expression in the hypothalamus [161]. Using immunochemistry, Sarruf et al. (2009)[161] confirmed the expression of PPAR $\gamma$ in several hypothalamic nuclei controlling energy balance, autonomic function and glucose metabolism particularly the ARC, VMH and LHA. PPAR $\gamma$ was found particularly localized within NPY/AgRP and POMC neurons suggesting a potential role in the integration of humoral signals. Interestingly, the authors demonstrated that PPAR $\gamma$ is also present within dopaminergic neurons of the ventral tegmental area (VTA), a brain region involved in the establishment of rewarding properties of food and other stimuli. Despite these observations, body weight and food intake were similar in mice lacking hypothalamic PPAR $\gamma$ expression fed a regular chow diet suggesting that PPAR $\gamma$ is not required for body weight regulation under basal conditions. Nevertheless, given its expression profile, the role of PPAR $\gamma$ in the central control of homeostasis awaits further investigation. In conclusion, data on the role of hypothalamic PPARs are scarce. Additional studies are needed to determine their role in the control of energy homeostasis by the brain, including humoral and nutrient sensing as well as the integration of these signals at the central level.

\subsection{LXRs}

LXRs are expressed in the CNS, notably the brain stem, hypothalamus and cortex [153]. As mentioned above, LXRs act as molecular sensors of intracellular cholesterol concentrations. Cholesterol is essential for the function of all eukaryotic cells, especially for membrane 
composition, membrane permeability/fluidity, endocytosis [162] and intracellular signaling [163-164]. This is particularly important for neurons since they are in need of tightlycontrolled ion balance, endocytosis and intracellular signaling [165]. The regulation of neuronal cholesterol content is thus important for synaptic functioning. Any imbalance in brain cholesterol levels will have severe consequences and may lead to critical disorders [166]. In the brain, oxysterol-activated LXRs exert neuroprotective mechanisms including the induction of ApoE and ABCA1 expression, enhancing cholesterol re-distribution and efflux, but also the induction of genes governing bile acid synthesis [167].

A study has shown that 24-(S)-hydroxycholesterol, a cholesterol metabolite, is a specific ligand of LXRs in the brain and mediates LXR-controlled regulation of cholesterol availability in the brain [168]. Given the important role of LXRs in cholesterol homeostasis which in turn is crucial for brain (patho)physiology, it is not surprising that hypothalamic LXRs play a role in hypothalamic cholesterol homeostasis. In addition, a recent study of Perez-Tilve et al. (2010)[169] shows a role for the melanocortin system in controlling hepatic cholesterol metabolism. Indeed, independent of food intake or body weight the pharmacological, genetic or endocrine inhibition of the melanocortin system increases circulating HDL cholesterol levels by reducing its uptake by the liver. This effect is mediated through vagal modulation of hepatic pathways known to be modulated by the ANS. Thus, it would be interesting to further elucidate the potential role of brain LXRs in this newly described control system of hepatic cholesterol metabolism implicating the ANS and the hypothalamic melanocortin system, especially taking into account the expression of LXRs in the brain stem (comprising NTS and DMV) which represents the link between the melanocortin system and the ANS.

\subsection{Rev-erb $\alpha$}

The NR Rev-erba improves the robustness circadian clock via an additional feedback loop. Clock and Bmal1 activate Rev-erb $\alpha$ transcription resulting in daily fluctuations of Rev-erb $\alpha$ expression, which in turn represses Bmal1 [170]. Thus, by their tightly controlled presence on the Bmal1 promoter the two NRs Rev-erb $\alpha$ and ROR $\alpha$ form a regulatory loop crucial for the proper timing of the core clock machinery [44]. Emerging evidence demonstrates that genes of the clock machinery such as Clock and Bmall directly influence energy homeostasis and that mutations in those genes lead to metabolic disorders [140,142]. Interestingly, Rev-erb $\alpha$ which is an important metabolic regulator of glucose, lipid and bile acid metabolism in 
peripheral tissues is expressed in both circadian ( $\mathrm{SCN}$ ) and energy (ARC) networks and also in the brain stem [153]. Thus, taking into account its expression in the brain and its peripheral metabolic functions, Rev-erb $\alpha$ appears as a good candidate for the integration of energy signals within the melanocortin system.

\section{Conclusion}

The increased prevalence of obesity and type 2 diabetes and related diseases is a critical public health concern. Many efforts attempt to improve our understanding of pathophysiological mechanisms underlying the development of these disorders with the aim to develop new and efficient therapeutic approaches. However, obviously, metabolic alterations are not only regulated at the peripheral level. The recent concept of central control of energy homeostasis raises the possibility that acting at the level of brain structures afford new avenues for therapeutic development. NRs are potential targets for metabolic disorders. However, a better knowledge of their central role is crucial to determine whether their peripheral and central action converge towards the same beneficial output in metabolically impaired conditions. Clearly, too little is known about the functions of NRs in the brain and particularly in regions involved in the control of energy homeostasis despite the known role of NRs as molecular sensors of nutritional changes. Therefore, a better and precise knowledge of the role of central, and particularly hypothalamic NRs, is crucial to evaluate the benefical outcome we can expect by their targeting in the context of T2D and related disorders. 


\section{References}

[1] J.M.Olefsky, Nuclear receptor minireview series, J. Biol. Chem. 276 (2001) 36863-36864. [2] D.J.Mangelsdorf, C.Thummel, M.Beato, P.Herrlich, G.Schütz, K.Umesono, B.Blumberg, P.Kastner, M.Mark, P.Chambon, R.M.Evans, The nuclear receptor superfamily: the second decade, Cell 83 (1995) 835-839.

[3] D.M.Lonard, B.W.O'Malley, The expanding cosmos of nuclear receptor coactivators, Cell 125 (2006) 411-414.

[4] P.Lefebvre, G.Chinetti, J.Fruchart, B.Staels, Sorting out the roles of ppar alpha in energy metabolism and vascular homeostasis, J. Clin. Invest. 116 (2006) 571-580.

[5] T.Aoyama, J.M.Peters, N.Iritani, T.Nakajima, K.Furihata, T.Hashimoto, F .J.Gonzalez, Altered constitutive expression of fatty acid-metabolizing enzymes in mice lacking the peroxisome proliferator-activated receptor alpha (pparalpha), J. Biol. Chem. 273 (1998) 56785684.

[6] D.D.Patel, B .L.Knight, D.Wiggins, S.M.Humphreys, G.F.Gibbons, Disturbances in the normal regulation of srebp-sensitive genes in ppar alpha-deficient mice, J. Lipid Res. 42 (2001) 328-337.

[7] K.Schoonjans, B.Staels, J.Auwerx, Role of the peroxisome proliferator-activated receptor (ppar) in mediating the effects of fibrates and fatty acids on gene expression, J. Lipid Res. 37 (1996) 907-925.

[8] S.Kersten, J.Seydoux, J.M.Peters, F.J.Gonzalez, B.Desvergne, W.Wahli, Peroxisome proliferator-activated receptor alpha mediates the adaptive response to fasting, J. Clin. Invest. 103 (1999) 1489-1498.

[9] T.Gulick, S.Cresci, T.Caira, D .D.Moore, D.P.Kelly, The peroxisome proliferatoractivated receptor regulates mitochondrial fatty acid oxidative enzyme gene expression, Proc. Natl. Acad. Sci. U.S.A. 91 (1994) 11012-11016.

[10] H.Keller, C.Dreyer, J.Medin, A.Mahfoudi, K.Ozato, W.Wahli, Fatty acids and retinoids control lipid metabolism through activation of peroxisome proliferator-activated receptorretinoid x receptor heterodimers, Proc. Natl. Acad. Sci. U.S.A. 90 (1993) 2160-2164.

[11] C.J.Chou, M.Haluzik, C.Gregory, K.R.Dietz, C.Vinson, O.Gavrilova, M.L.Reitman, Wy14,643, a peroxisome proliferator-activated receptor alpha (pparalpha ) agonist, improves hepatic and muscle steatosis and reverses insulin resistance in lipoatrophic a-zip/f-1 mice, J. Biol. Chem. 277 (2002) 24484-24489.

[12] H.Kim, M.Haluzik, Z.Asghar, D.Yau, J .W.Joseph, A.M.Fernandez, M.L.Reitman, S.Yakar, B.Stannard, L.Heron-Milhavet, M .B.Wheeler, D.LeRoith, Peroxisome proliferatoractivated receptor-alpha agonist treatment in a transgenic model of type 2 diabetes reverses the lipotoxic state and improves glucose homeostasis, Diabetes 52 (2003) 1770-1778.

[13] M.Guerre-Millo, P.Gervois, E.Raspé, L.Madsen, P.Poulain, B.Derudas, J.M.Herbert, D.A.Winegar, T.M.Willson, J.C.Fruchart, R.K.Berge, B.Staels, Peroxisome proliferatoractivated receptor alpha activators improve insulin sensitivity and reduce adiposity, J. Biol. Chem. 275 (2000) 16638-16642.

[14] F.Lalloyer, B.Staels, Fibrates, glitazones, and peroxisome proliferator-activated receptors, Arterioscler. Thromb. Vasc. Biol. 30 (2010) 894-899.

[15] B.Staels, Fibrates in cvd: a step towards personalised medicine, Lancet 375 (2010) 1847 1848.

[16] B.Staels, Ppar agonists and the metabolic syndrome, Therapie 62 (2007) 319-326.

[17] J.N.Feige, L.Gelman, L.Michalik, B.Desvergne, W.Wahli, From molecular action to physiological outputs: peroxisome proliferator-activated receptors are nuclear receptors at the crossroads of key cellular functions, Prog. Lipid Res. 45 (2006) 120-159. 
[18] P.Tontonoz, E.Hu, B.M.Spiegelman, Regulation of adipocyte gene expression and differentiation by peroxisome proliferator activated receptor gamma, Curr. Opin. Genet. Dev. 5 (1995) 571-576.

[19] K.Schoonjans, B.Staels, J.Auwerx, The peroxisome proliferator activated receptors (ppars) and their effects on lipid metabolism and adipocyte differentiation, Biochim. Biophys. Acta 1302 (1996) 93-109.

[20] E.D.Rosen, P.Sarraf, E.Troy, G.Bradwin, K.Moore, D.S.Milstone, B.M.Spiegelman, R.M.Mortensen, Ppar gamma is required for the differentiation of adipose tissue in vivo and in vitro, Mol. Cell 4 (1999) 611-617.

[21] P.Tontonoz, E.Hu, B.M.Spiegelman, Stimulation of adipogenesis in fibroblasts by ppar gamma 2, a lipid-activated transcription factor, Cell 79 (1994) 1147-1156.

[22] A.M.Sharma, B.Staels, Review: peroxisome proliferator-activated receptor gamma and adipose tissue--understanding obesity-related changes in regulation of lipid and glucose metabolism, J. Clin. Endocrinol. Metab. 92 (2007) 386-395.

[23] I.Bogacka, H.Xie, G.A.Bray, S.R.Smith, The effect of pioglitazone on peroxisome proliferator-activated receptor-gamma target genes related to lipid storage in vivo, Diabetes Care 27 (2004) 1660-1667.

[24] A.L.Hevener, W.He, Y.Barak, J.Le, G.Bandyopadhyay, P.Olson, J.Wilkes, R.M.Evans, J.Olefsky, Muscle-specific pparg deletion causes insulin resistance, Nat. Med. 9 (2003) 14911497.

[25] W.He, Y.Barak, A.Hevener, P.Olson, D.Liao, J.Le, M.Nelson, E.Ong, J.M.Olefsky, R.M.Evans, Adipose-specific peroxisome proliferator-activated receptor gamma knockout causes insulin resistance in fat and liver but not in muscle, Proc. Natl. Acad. Sci. U.S.A. 100 (2003) 15712-15717.

[26] N.Kubota, Y.Terauchi, H.Miki, H.Tamemoto, T.Yamauchi, K.Komeda, S.Satoh, R.Nakano, C.Ishii, T.Sugiyama, K.Eto, Y.Tsubamoto, A.Okuno, K.Murakami, H.Sekihara, G.Hasegawa, M.Naito, Y.Toyoshima, S.Tanaka, K.Shiota, T.Kitamura, T.Fujita, O.Ezaki, S.Aizawa, T.Kadowaki, et al., Ppar gamma mediates high-fat diet-induced adipocyte hypertrophy and insulin resistance, Mol. Cell 4 (1999) 597-609.

[27] E.Chaput, R.Saladin, M.Silvestre, A .D.Edgar, Fenofibrate and rosiglitazone lower serum triglycerides with opposing effects on body weight, Biochem. Biophys. Res. Commun. 271 (2000) 445-450.

[28] L.C.Pickavance, R.E.Buckingham, J.P.Wilding, Insulin-sensitizing action of rosiglitazone is enhanced by preventing hyperphagia, Diabetes Obes Metab 3 (2001) 171-180.

[29] J.J.Repa, D .J.Mangelsdorf, The role of orphan nuclear receptors in the regulation of cholesterol homeostasis, Annu. Rev. Cell Dev. Biol. 16 (2000) 459-481.

[30] J.Vaya, H.M.Schipper, Oxysterols, cholesterol homeostasis, and alzheimer disease, J. Neurochem. 102 (2007) 1727-1737.

[31] J.R.Schultz, H.Tu, A.Luk, J .J.Repa, J .C.Medina, L.Li, S.Schwendner, S.Wang, M.Thoolen, D .J.Mangelsdorf, K .D.Lustig, B.Shan, Role of lxrs in control of lipogenesis, Genes Dev. 14 (2000) 2831-2838.

[32] D.J.Peet, S .D.Turley, W.Ma, B .A.Janowski, J .M.Lobaccaro, R .E.Hammer, D .J.Mangelsdorf, Cholesterol and bile acid metabolism are impaired in mice lacking the nuclear oxysterol receptor lxr alpha, Cell 93 (1998) 693-704.

[33] B.A.Laffitte, L .C.Chao, J.Li, R.Walczak, S.Hummasti, S .B.Joseph, A.Castrillo, D.C.Wilpitz, D .J.Mangelsdorf, J .L.Collins, E.Saez, P.Tontonoz, Activation of liver $\mathrm{x}$ receptor improves glucose tolerance through coordinate regulation of glucose metabolism in liver and adipose tissue, Proc. Natl. Acad. Sci. U.S.A. 100 (2003) 5419-5424.

[34] G.Cao, Y.Liang, C.L.Broderick, B.A.Oldham, T.P.Beyer, R.J.Schmidt, Y.Zhang, K.R.Stayrook, C.Suen, K.A.Otto, A.R.Miller, J.Dai, P.Foxworthy, H.Gao, T.P.Ryan, X.Jiang, 
T.P.Burris, P.I.Eacho, G.J.Etgen, Antidiabetic action of a liver x receptor agonist mediated by inhibition of hepatic gluconeogenesis, J. Biol. Chem. 278 (2003) 1131-1136.

[35] S.Alberti, G.Schuster, P.Parini, D.Feltkamp, U.Diczfalusy, M.Rudling, B.Angelin, I.Björkhem, S.Pettersson, J .A.Gustafsson, Hepatic cholesterol metabolism and resistance to dietary cholesterol in lxrbeta-deficient mice, J. Clin. Invest. 107 (2001) 565-573.

[36] B.A.Janowski, M.J.Grogan, S.A.Jones, G.B.Wisely, S.A.Kliewer, E.J.Corey, D.J.Mangelsdorf, Structural requirements of ligands for the oxysterol liver $\mathrm{x}$ receptors 1xralpha and lxrbeta, Proc. Natl. Acad. Sci. U.S.A. 96 (1999) 266-271.

[37] B.A.Janowski, P.J.Willy, T.R.Devi, J.R.Falck, D.J.Mangelsdorf, An oxysterol signalling pathway mediated by the nuclear receptor lxr alpha, Nature 383 (1996) 728-731.

[38] M.Heverin, S.Meaney, A.Brafman, M.Shafir, M.Olin, M.Shafaati, S.von Bahr, L.Larsson, A.Lövgren-Sandblom, U.Diczfalusy, P.Parini, E.Feinstein, I.Björkhem, Studies on the cholesterol-free mouse: strong activation of lxr-regulated hepatic genes when replacing cholesterol with desmosterol, Arterioscler. Thromb. Vasc. Biol. 27 (2007) 2191-2197.

[39] C.Yang, J.G.McDonald, A.Patel, Y.Zhang, M.Umetani, F.Xu, E .J.Westover, D .F.Covey, D .J.Mangelsdorf, J .C.Cohen, H .H.Hobbs, Sterol intermediates from cholesterol biosynthetic pathway as liver x receptor ligands, J. Biol. Chem. 281 (2006) 27816-27826.

[40] K.R.Steffensen, M.Nilsson, G .U.Schuster, T .M.Stulnig, K.Dahlman-Wright, J.Gustafsson, Gene expression profiling in adipose tissue indicates different transcriptional mechanisms of liver $\mathrm{x}$ receptors alpha and beta, respectively, Biochem. Biophys. Res. Commun. 310 (2003) 589-593.

[41] J.J.Repa, G.Liang, J.Ou, Y.Bashmakov, J .M.Lobaccaro, I.Shimomura, B.Shan, M .S.Brown, J .L.Goldstein, D .J.Mangelsdorf, Regulation of mouse sterol regulatory elementbinding protein-1c gene (srebp-1c) by oxysterol receptors, 1xralpha and lxrbeta, Genes Dev. 14 (2000) 2819-2830.

[42] E.G.Lund, L .B.Peterson, A .D.Adams, M .N.Lam, C .A.Burton, J.Chin, Q.Guo, S.Huang, M.Latham, J .C.Lopez, J .G.Menke, D .P.Milot, L .J.Mitnaul, S .E.Rex-Rabe, R .L.Rosa, J .Y.Tian, S .D.Wright, C .P.Sparrow, Different roles of liver x receptor alpha and beta in lipid metabolism: effects of an alpha-selective and a dual agonist in mice deficient in each subtype, Biochem. Pharmacol. 71 (2006) 453-463.

[43] T.Nomiyama, D.Bruemmer, Liver x receptors as therapeutic targets in metabolism and atherosclerosis, Curr Atheroscler Rep 10 (2008) 88-95.

[44] H.Duez, B.Staels, Nuclear receptors linking circadian rhythms and cardiometabolic control, Arterioscler. Thromb. Vasc. Biol. 30 (2010) 1529-1534.

[45] S.Zvonic, A .A.Ptitsyn, S .A.Conrad, L .K.Scott, Z .E.Floyd, G.Kilroy, X.Wu, B .C.Goh, R .L.Mynatt, J .M.Gimble, Characterization of peripheral circadian clocks in adipose tissues, Diabetes 55 (2006) 962-970.

[46] E.Mühlbauer, S.Wolgast, U.Finckh, D.Peschke, E.Peschke, Indication of circadian oscillations in the rat pancreas, FEBS Lett. 564 (2004) 91-96.

[47] X.Yang, M.Downes, R.T.Yu, A .L.Bookout, W.He, M.Straume, D .J.Mangelsdorf, R .M.Evans, Nuclear receptor expression links the circadian clock to metabolism, Cell 126 (2006) 801-810.

[48] S.Panda, M.P.Antoch, B .H.Miller, A .I.Su, A .B.Schook, M.Straume, P .G.Schultz, S.A.Kay, J .S.Takahashi, J .B.Hogenesch, Coordinated transcription of key pathways in the mouse by the circadian clock, Cell 109 (2002) 307-320.

[49] L.Yin, N.Wu, J.C.Curtin, M.Qatanani, N .R.Szwergold, R .A.Reid, G .M.Waitt, D .J.Parks, K .H.Pearce, G .B.Wisely, M .A.Lazar, Rev-erbalpha, a heme sensor that coordinates metabolic and circadian pathways, Science 318 (2007) 1786-1789. 
[50] E.Raspé, H.Duez, A.Mansén, C.Fontaine, C.Fiévet, J.Fruchart, B.Vennström, B.Staels, Identification of rev-erbalpha as a physiological repressor of apoc-iii gene transcription, J. Lipid Res. 43 (2002) 2172-2179.

[51] N.Vu-Dac, S.Chopin-Delannoy, P.Gervois, E.Bonnelye, G.Martin, J.C.Fruchart, V.Laudet, B.Staels, The nuclear receptors peroxisome proliferator-activated receptor alpha and rev-erbalpha mediate the species-specific regulation of apolipoprotein a-i expression by fibrates, J. Biol. Chem. 273 (1998) 25713-25720.

[52] H.Duez, J.N.van der Veen, C.Duhem, B.Pourcet, T.Touvier, C.Fontaine, B.Derudas, E.Baugé, R.Havinga, V .W.Bloks, H.Wolters, F .H.van der Sluijs, B.Vennström, F.Kuipers, B.Staels, Regulation of bile acid synthesis by the nuclear receptor rev-erbalpha, Gastroenterology 135 (2008) 689-698.

[53] J.Wang, M.A.Lazar, Bifunctional role of rev-erbalpha in adipocyte differentiation, Mol. Cell. Biol. 28 (2008) 2213-2220.

[54] C.Fontaine, G.Dubois, Y.Duguay, T.Helledie, N.Vu-Dac, P.Gervois, F.Soncin, S.Mandrup, J.Fruchart, J.Fruchart-Najib, B.Staels, The orphan nuclear receptor rev-erbalpha is a peroxisome proliferator-activated receptor (ppar) gamma target gene and promotes ppargamma-induced adipocyte differentiation, J. Biol. Chem. 278 (2003) 37672-37680.

[55] P.Pircher, P.Chomez, F.Yu, B.Vennström, L.Larsson, Aberrant expression of myosin isoforms in skeletal muscles from mice lacking the rev-erbaalpha orphan receptor gene, Am. J. Physiol. Regul. Integr. Comp. Physiol. 288 (2005) R482-90.

[56] C.Blouet, G.J.Schwartz, Hypothalamic nutrient sensing in the control of energy homeostasis, Behav. Brain Res. 209 (2010) 1-12.

[57] S.Obici, Minireview: molecular targets for obesity therapy in the brain, Endocrinology 150 (2009) 2512-2517.

[58] C.Sánchez-Lasheras, A.C.Könner, J .C.Brüning, Integrative neurobiology of energy homeostasis-neurocircuits, signals and mediators, Front Neuroendocrinol 31 (2010) 4-15.

[59] R.J.Seeley, S .C.Woods, Monitoring of stored and available fuel by the cns: implications for obesity, Nat. Rev. Neurosci. 4 (2003) 901-909.

[60] G.J.Morton, D .E.Cummings, D .G.Baskin, G .S.Barsh, M .W.Schwartz, Central nervous system control of food intake and body weight, Nature 443 (2006) 289-295.

[61] S.C.Woods, D.A.D'Alessio, Central control of body weight and appetite, J. Clin. Endocrinol. Metab. 93 (2008) S37-50.

[62] S.C.Woods, R.J.Seeley, D .J.Porte, M .W.Schwartz, Signals that regulate food intake and energy homeostasis, Science 280 (1998) 1378-1383.

[63] M.W.Schwartz, S .C.Woods, D .J.Porte, R .J.Seeley, D .G.Baskin, Central nervous system control of food intake, Nature 404 (2000) 661-671.

[64] J.D.Bagdade, E.L.Bierman, D .J.Porte, The significance of basal insulin levels in the evaluation of the insulin response to glucose in diabetic and nondiabetic subjects, J. Clin. Invest. 46 (1967) 1549-1557.

[65] C.T.Montague, I.S.Farooqi, J.P.Whitehead, M.A.Soos, H.Rau, N.J.Wareham, C .P.Sewter, J .E.Digby, S.N.Mohammed, J.A.Hurst, C.H.Cheetham, A .R.Earley, A .H.Barnett, J .B.Prins, S.O'Rahilly, Congenital leptin deficiency is associated with severe early-onset obesity in humans, Nature 387 (1997) 903-908.

[66] A.Dua, M.I.Hennes, R .G.Hoffmann, D .L.Maas, G .R.Krakower, G.E.Sonnenberg, A .H.Kissebah, Leptin: a significant indicator of total body fat but not of visceral fat and insulin insensitivity in african-american women, Diabetes 45 (1996) 1635-1637.

[67] H.Masuzaki, Y.Ogawa, N.Isse, N.Satoh, T.Okazaki, M.Shigemoto, K.Mori, N.Tamura, K.Hosoda, Y.Yoshimasa, et al., Human obese gene expression. adipocyte-specific expression and regional differences in the adipose tissue, Diabetes 44 (1995) 855-858. 
[68] R.D.Cone, Anatomy and regulation of the central melanocortin system, Nat. Neurosci. 8 (2005) 571-578.

[69] D.Spanswick, M.A.Smith, V.E.Groppi, S .D.Logan, M .L.Ashford, Leptin inhibits hypothalamic neurons by activation of atp-sensitive potassium channels, Nature 390 (1997) 521-525.

[70] M.A.Cowley, J.L.Smart, M.Rubinstein, M.G.Cerdán, S.Diano, T .L.Horvath, R .D.Cone, $M$.J.Low, Leptin activates anorexigenic pomc neurons through a neural network in the arcuate nucleus, Nature 411 (2001) 480-484.

[71] C .F.Elias, C.Aschkenasi, C.Lee, J.Kelly, R .S.Ahima, C.Bjorbaek, J .S.Flier, C .B.Saper, J .K.Elmquist, Leptin differentially regulates npy and pomc neurons projecting to the lateral hypothalamic area, Neuron 23 (1999) 775-786.

[72] M.W.Schwartz, R.J.Seeley, L.A.Campfield, P.Burn, D.G.Baskin, Identification of targets of leptin action in rat hypothalamus, J. Clin. Invest. 98 (1996) 1101-1106.

[73] J.M.Zigman, J.K.Elmquist, Minireview: from anorexia to obesity--the yin and yang of body weight control, Endocrinology 144 (2003) 3749-3756.

[74] L.Plum, B.F.Belgardt, J .C.Brüning, Central insulin action in energy and glucose homeostasis, J. Clin. Invest. 116 (2006) 1761-1766.

[75] L.Plum, X.Ma, B.Hampel, N.Balthasar, R.Coppari, H.Münzberg, M.Shanabrough, D.Burdakov, E.Rother, R.Janoschek, J.Alber, B .F.Belgardt, L.Koch, J.Seibler, F.Schwenk, C.Fekete, A.Suzuki, T .W.Mak, W.Krone, T .L.Horvath, F .M.Ashcroft, J .C.Brüning, Enhanced pip3 signaling in pomc neurons causes katp channel activation and leads to dietsensitive obesity, J. Clin. Invest. 116 (2006) 1886-1901.

[76] A.C.Könner, R.Janoschek, L.Plum, S .D.Jordan, E.Rother, X.Ma, C.Xu, P.Enriori, B.Hampel, G .S.Barsh, C .R.Kahn, M .A.Cowley, F .M.Ashcroft, J .C.Brüning, Insulin action in agrp-expressing neurons is required for suppression of hepatic glucose production, Cell Metab 5 (2007) 438-449.

[77] T.K.T.Lam, G.J.Schwartz, L.Rossetti, Hypothalamic sensing of fatty acids, Nat. Neurosci. 8 (2005) 579-584.

[78] L.Pénicaud, C.Leloup, X.Fioramonti, A.Lorsignol, A.Benani, Brain glucose sensing: a subtle mechanism, Curr Opin Clin Nutr Metab Care 9 (2006) 458-462.

[79] B .E.Levin, Metabolic sensing neurons and the control of energy homeostasis, Physiol. Behav. 89 (2006) 486-489.

[80] J.Mayer, Glucostatic mechanism of regulation of food intake. 1953, Obes. Res. 4 (1996) 493-496.

[81] S.D.Jordan, A .C.Könner, J .C.Brüning, Sensing the fuels: glucose and lipid signaling in the cns controlling energy homeostasis, Cell. Mol. Life Sci. 67 (2010) 3255-3273.

[82] M.L.Ashford, P .R.Boden, J .M.Treherne, Glucose-induced excitation of hypothalamic neurones is mediated by atp-sensitive k+ channels, Pflugers Arch. 415 (1990) 479-483.

[83] S.Muroya, T.Yada, S.Shioda, M.Takigawa, Glucose-sensitive neurons in the rat arcuate nucleus contain neuropeptide y, Neurosci. Lett. 264 (1999) 113-116.

[84] N.Ibrahim, M .A.Bosch, J .L.Smart, J.Qiu, M.Rubinstein, O .K.Rønnekleiv, M .J.Low, M .J.Kelly, Hypothalamic proopiomelanocortin neurons are glucose responsive and express k(atp) channels, Endocrinology 144 (2003) 1331-1340.

[85] K.Kurata, K.Fujimoto, T.Sakata, H.Etou, K.Fukagawa, D-glucose suppression of eating after intra-third ventricle infusion in rat, Physiol. Behav. 37 (1986) 615-620.

[86] J.Panksepp, J.Rossi, D-glucose infusions into the basal ventromedial hypothalamus and feeding, Behav. Brain Res. 3 (1981) 381-392.

[87] J.D.Davis, D.Wirtshafter, K .E.Asin, D.Brief, Sustained intracerebroventricular infusion of brain fuels reduces body weight and food intake in rats, Science 212 (1981) 81-83. 
[88] H.R.Berthoud, G.J.Mogenson, Ingestive behavior after intracerebral and intracerebroventricular infusions of glucose and 2-deoxy-d-glucose, Am. J. Physiol. 233 (1977) R127-33.

[89] R.R.Miselis, A .N.Epstein, Feeding induced by intracerebroventricular 2-deoxy-dglucose in the rat, Am. J. Physiol. 229 (1975) 1438-1447.

[90] S.Ritter, T.T.Dinh, Y.Zhang, Localization of hindbrain glucoreceptive sites controlling food intake and blood glucose, Brain Res. 856 (2000) 37-47.

[91] S.Ritter, K.Bugarith, T.T.Dinh, Immunotoxic destruction of distinct catecholamine subgroups produces selective impairment of glucoregulatory responses and neuronal activation, J. Comp. Neurol. 432 (2001) 197-216.

[92] B.Thorens, Glucose sensing and the pathogenesis of obesity and type 2 diabetes, Int $\mathbf{J}$ Obes (Lond) 32 Suppl 6 (2008) S62-71.

[93] M.Claret, M.A.Smith, R .L.Batterham, C.Selman, A .I.Choudhury, L .G .D.Fryer, M.Clements, H.Al-Qassab, H.Heffron, A .W.Xu, J .R.Speakman, G .S.Barsh, B.Viollet, S.Vaulont, M .L .J.Ashford, D.Carling, D .J.Withers, Ampk is essential for energy homeostasis regulation and glucose sensing by pomc and agrp neurons, J. Clin. Invest. 117 (2007) 2325-2336.

[94] Y.Jo, Y.Su, R.Gutierrez-Juarez, S .J.Chua, Oleic acid directly regulates pomc neuron excitability in the hypothalamus, J. Neurophysiol. 101 (2009) 2305-2316.

[95] C.Le Foll, B .G.Irani, C.Magnan, A .A.Dunn-Meynell, B .E.Levin, Characteristics and mechanisms of hypothalamic neuronal fatty acid sensing, Am. J. Physiol. Regul. Integr. Comp. Physiol. 297 (2009) R655-64.

[96] M.López, A.Vidal-Puig, Brain lipogenesis and regulation of energy metabolism, Curr Opin Clin Nutr Metab Care 11 (2008) 483-490.

[97] M.López, C.J.Lelliott, A.Vidal-Puig, Hypothalamic fatty acid metabolism: a housekeeping pathway that regulates food intake, Bioessays 29 (2007) 248-261.

[98] R.Wang, C.Cruciani-Guglielmacci, S.Migrenne, C.Magnan, V .E.Cotero, V .H.Routh, Effects of oleic acid on distinct populations of neurons in the hypothalamic arcuate nucleus are dependent on extracellular glucose levels, J. Neurophysiol. 95 (2006) 1491-1498.

[99] W.M.Sperry, H.Waelshand V.A.Stoynanoff, Lipid metabolism in brain and other tissues of the rat, J. Biol.Chem 135 (1940) 281-290.

[100] K.Qi, M.Hall, R.J.Deckelbaum, Long-chain polyunsaturated fatty acid accretion in brain, Curr Opin Clin Nutr Metab Care 5 (2002) 133-138.

[101] J.Edmond, Essential polyunsaturated fatty acids and the barrier to the brain: the components of a model for transport, J. Mol. Neurosci. 16 (2001) 181-93; discussion 215-21.

[102] A.Stahl, R.E.Gimeno, L .A.Tartaglia, H .F.Lodish, Fatty acid transport proteins: a current view of a growing family, Trends Endocrinol. Metab. 12 (2001) 266-273.

[103] S.I.Rapoport, M .C.Chang, A .A.Spector, Delivery and turnover of plasma-derived essential pufas in mammalian brain, J. Lipid Res. 42 (2001) 678-685.

[104] M.López, S.Tovar, M.J.Vázquez, R.Nogueiras, R.Señarís, C.Diéguez, Sensing the fat: fatty acid metabolism in the hypothalamus and the melanocortin system, Peptides 26 (2005) $1753-1758$.

[105] E.Kim, I.Miller, L.E.Landree, F .F.Borisy-Rudin, P.Brown, T.Tihan, C .A.Townsend, L .A.Witters, T .H.Moran, F .P.Kuhajda, G .V.Ronnett, Expression of fas within hypothalamic neurons: a model for decreased food intake after c75 treatment, Am. J. Physiol. Endocrinol. Metab. 283 (2002) E867-79.

[106] A.Sorensen, M.T.Travers, R.G.Vernon, N .T.Price, M .C.Barber, Localization of messenger rnas encoding enzymes associated with malonyl-coa metabolism in mouse brain, Brain Res. Gene Expr. Patterns 1 (2002) 167-173. 
[107] T.Shimokawa, M.V.Kumar, M .D.Lane, Effect of a fatty acid synthase inhibitor on food intake and expression of hypothalamic neuropeptides, Proc. Natl. Acad. Sci. U.S.A. 99 (2002) 66-71.

[108] T.M.Loftus, D .E.Jaworsky, G .L.Frehywot, C .A.Townsend, G .V.Ronnett, M .D.Lane, F .P.Kuhajda, Reduced food intake and body weight in mice treated with fatty acid synthase inhibitors, Science 288 (2000) 2379-2381.

[109] M.D.Lane, M.Wolfgang, S.Cha, Y.Dai, Regulation of food intake and energy expenditure by hypothalamic malonyl-coa, Int J Obes (Lond) 32 Suppl 4 (2008) S49-54.

[110] S.Gao, M.D.Lane, Effect of the anorectic fatty acid synthase inhibitor c75 on neuronal activity in the hypothalamus and brainstem, Proc. Natl. Acad. Sci. U.S.A. 100 (2003) 56285633.

[111] M.López, C.J.Lelliott, S.Tovar, W.Kimber, R.Gallego, S.Virtue, M.Blount, M .J.Vázquez, N.Finer, T .J.Powles, S.O'Rahilly, A .K.Saha, C.Diéguez, A .J.Vidal-Puig, Tamoxifen-induced anorexia is associated with fatty acid synthase inhibition in the ventromedial nucleus of the hypothalamus and accumulation of malonyl-coa, Diabetes 55 (2006) 1327-1336.

[112] Z.Hu, S.H.Cha, S.Chohnan, M .D.Lane, Hypothalamic malonyl-coa as a mediator of feeding behavior, Proc. Natl. Acad. Sci. U.S.A. 100 (2003) 12624-12629.

[113] Y.Minokoshi, T.Alquier, N.Furukawa, Y.Kim, A.Lee, B.Xue, J.Mu, F.Foufelle, P.Ferré, M.J.Birnbaum, B .J.Stuck, B .B.Kahn, Amp-kinase regulates food intake by responding to hormonal and nutrient signals in the hypothalamus, Nature 428 (2004) 569-574.

[114] M.López, R.Lage, A.K.Saha, D.Pérez-Tilve, M .J.Vázquez, L.Varela, S.SangiaoAlvarellos, S.Tovar, K.Raghay, S.Rodríguez-Cuenca, R .M.Deoliveira, T.Castañeda, R.Datta, J .Z.Dong, M.Culler, M .W.Sleeman, C .V.Alvarez, R.Gallego, C .J.Lelliott, D.Carling, M .H.Tschöp, C.Diéguez, A.Vidal-Puig, Hypothalamic fatty acid metabolism mediates the orexigenic action of ghrelin, Cell Metab 7 (2008) 389-399.

[115] N.Kubota, W.Yano, T.Kubota, T.Yamauchi, S.Itoh, H.Kumagai, H.Kozono, I.Takamoto, S.Okamoto, T.Shiuchi, R.Suzuki, H.Satoh, A.Tsuchida, M.Moroi, K.Sugi, T.Noda, H.Ebinuma, Y.Ueta, T.Kondo, E.Araki, O.Ezaki, R.Nagai, K.Tobe, Y.Terauchi, K.Ueki, Y.Minokoshi, T.Kadowaki, Adiponectin stimulates amp-activated protein kinase in the hypothalamus and increases food intake, Cell Metab 6 (2007) 55-68.

[116] B.Kola, E.Hubina, S.A.Tucci, T .C.Kirkham, E .A.Garcia, S .E.Mitchell, L .M.Williams, S .A.Hawley, D .G.Hardie, A .B.Grossman, M.Korbonits, Cannabinoids and ghrelin have both central and peripheral metabolic and cardiac effects via amp-activated protein kinase, J. Biol. Chem. 280 (2005) 25196-25201.

[117] Z.B.Andrews, Z.Liu, N.Walllingford, D .M.Erion, E.Borok, J .M.Friedman, M .H.Tschöp, M.Shanabrough, G.Cline, G .I.Shulman, A.Coppola, X.Gao, T .L.Horvath, S.Diano, Ucp2 mediates ghrelin's action on npy/agrp neurons by lowering free radicals, Nature 454 (2008) 846-851.

[118] U.Andersson, K.Filipsson, C.R.Abbott, A.Woods, K.Smith, S .R.Bloom, D.Carling, C .J.Small, Amp-activated protein kinase plays a role in the control of food intake, J. Biol. Chem. 279 (2004) 12005-12008.

[119] M.J.Wolfgang, S .H.Cha, A.Sidhaye, S.Chohnan, G.Cline, G .I.Shulman, M .D.Lane, Regulation of hypothalamic malonyl-coa by central glucose and leptin, Proc. Natl. Acad. Sci. U.S.A. 104 (2007) 19285-19290.

[120] S.Seo, S.Ju, H.Chung, D.Lee, S.Park, Acute effects of glucagon-like peptide-1 on hypothalamic neuropeptide and amp activated kinase expression in fasted rats, Endocr. J. 55 (2008) 867-874. 
[121] C.Namkoong, M.S.Kim, P .G.Jang, S .M.Han, H .S.Park, E .H.Koh, W .J.Lee, J .Y.Kim, I .S.Park, J .Y.Park, K .U.Lee, Enhanced hypothalamic amp-activated protein kinase activity contributes to hyperphagia in diabetic rats, Diabetes 54 (2005) 63-68.

[122] B.M.Spiegelman, J .S.Flier, Obesity and the regulation of energy balance, Cell 104 (2001) 531-543.

[123] M.Palkovits, Interconnections between the neuroendocrine hypothalamus and the central autonomic system, Geoffrey Harris Memorial Lecture, Kitakyushu, Japan, October 1998Front Neuroendocrinol 20 (1999) 270-295.

[124] L.W.Swanson, P .E.Sawchenko, Paraventricular nucleus: a site for the integration of neuroendocrine and autonomic mechanisms, Neuroendocrinology 31 (1980) 410-417.

[125] H.Kawano, S.Masuko, Beta-endorphin-, adrenocorticotrophic hormone- and neuropeptide y-containing projection fibers from the arcuate hypothalamic nucleus make synaptic contacts on to nucleus preopticus medianus neurons projecting to the paraventricular hypothalamic nucleus in the rat, Neuroscience 98 (2000) 555-565.

[126] M.A.Cowley, N.Pronchuk, W.Fan, D .M.Dinulescu, W .F.Colmers, R .D.Cone, Integration of npy, agrp, and melanocortin signals in the hypothalamic paraventricular nucleus: evidence of a cellular basis for the adipostat, Neuron 24 (1999) 155-163.

[127] C.B.Saper, J.Lu, T .C.Chou, J.Gooley, The hypothalamic integrator for circadian rhythms, Trends Neurosci. 28 (2005) 152-157.

[128] H.Münzberg, Differential leptin access into the brain--a hierarchical organization of hypothalamic leptin target sites?, Physiol. Behav. 94 (2008) 664-669.

[129] T.Sakurai, A.Amemiya, M.Ishii, I.Matsuzaki, R.M.Chemelli, H.Tanaka, S .C.Williams, J .A.Richardson, G .P.Kozlowski, S.Wilson, J .R.Arch, R .E.Buckingham, A .C.Haynes, S.A.Carr, R .S.Annan, D .E.McNulty, W .S.Liu, J .A.Terrett, N .A.Elshourbagy, D.J.Bergsma, M.Yanagisawa, Orexins and orexin receptors: a family of hypothalamic neuropeptides and $g$ protein-coupled receptors that regulate feeding behavior, Cell 92 (1998) 573-585.

[130] G.Segal-Lieberman, R.L.Bradley, E.Kokkotou, M.Carlson, D .J.Trombly, X.Wang, S.Bates, M .G .J.Myers, J .S.Flier, E.Maratos-Flier, Melanin-concentrating hormone is a critical mediator of the leptin-deficient phenotype, Proc. Natl. Acad. Sci. U.S.A. 100 (2003) 10085-10090.

[131] D.S.Ludwig, N .A.Tritos, J .W.Mastaitis, R.Kulkarni, E.Kokkotou, J.Elmquist, B.Lowell, J .S.Flier, E.Maratos-Flier, Melanin-concentrating hormone overexpression in transgenic mice leads to obesity and insulin resistance, J. Clin. Invest. 107 (2001) 379-386.

[132] C.R.Abbott, A .R.Kennedy, A .M.Wren, M.Rossi, K .G.Murphy, L .J.Seal, J .F.Todd, M .A.Ghatei, C .J.Small, S .R.Bloom, Identification of hypothalamic nuclei involved in the orexigenic effect of melanin-concentrating hormone, Endocrinology 144 (2003) 3943-3949.

[133] M.van den Top, K.Lee, A.D.Whyment, A .M.Blanks, D.Spanswick, Orexigen-sensitive npy/agrp pacemaker neurons in the hypothalamic arcuate nucleus, Nat. Neurosci. 7 (2004) 493-494.

[134] S.Muroya, H.Funahashi, A.Yamanaka, D.Kohno, K.Uramura, T.Nambu, M.Shibahara, M.Kuramochi, M.Takigawa, M.Yanagisawa, T.Sakurai, S.Shioda, T.Yada, Orexins (hypocretins) directly interact with neuropeptide y, pomc and glucose-responsive neurons to regulate ca 2+ signaling in a reciprocal manner to leptin: orexigenic neuronal pathways in the mediobasal hypothalamus, Eur. J. Neurosci. 19 (2004) 1524-1534.

[135] X.Ma, L.Zubcevic, J.C.Brüning, F .M.Ashcroft, D.Burdakov, Electrical inhibition of identified anorexigenic pomc neurons by orexin/hypocretin, J. Neurosci. 27 (2007) 15291533.

[136] H.Zheng, L.M.Patterson, C.Morrison, B .W.Banfield, J .A.Randall, K .N.Browning, R .A.Travagli, H.Berthoud, Melanin concentrating hormone innervation of caudal brainstem 
areas involved in gastrointestinal functions and energy balance, Neuroscience 135 (2005) 611-625.

[137] H.Berthoud, Multiple neural systems controlling food intake and body weight, Neurosci Biobehav Rev 26 (2002) 393-428.

[138] K.Ohno, T.Sakurai, Orexin neuronal circuitry: role in the regulation of sleep and wakefulness, Front Neuroendocrinol 29 (2008) 70-87.

[139] M.R.Castillo, K .J.Hochstetler, R .J .J.Tavernier, D .M.Greene, A.Bult-Ito, Entrainment of the master circadian clock by scheduled feeding, Am. J. Physiol. Regul. Integr. Comp. Physiol. 287 (2004) R551-5.

[140] F.W.Turek, C.Joshu, A.Kohsaka, E.Lin, G.Ivanova, E.McDearmon, A.Laposky, S.Losee-Olson, A.Easton, D .R.Jensen, R .H.Eckel, J .S.Takahashi, J.Bass, Obesity and metabolic syndrome in circadian clock mutant mice, Science 308 (2005) 1043-1045.

[141] R.D.Rudic, P.McNamara, A.Curtis, R .C.Boston, S.Panda, J .B.Hogenesch, G .A.Fitzgerald, Bmal1 and clock, two essential components of the circadian clock, are involved in glucose homeostasis, PLoS Biol. 2 (2004) e377.

[142] E.M.Scott, A .M.Carter, P .J.Grant, Association between polymorphisms in the clock gene, obesity and the metabolic syndrome in man, Int J Obes (Lond) 32 (2008) 658-662.

[143] F.Kreier, Y.S.Kap, T .C.Mettenleiter, C.van Heijningen, J.van der Vliet, A.Kalsbeek, H.P.Sauerwein, E.Fliers, J .A.Romijn, R .M.Buijs, Tracing from fat tissue, liver, and pancreas: a neuroanatomical framework for the role of the brain in type 2 diabetes, Endocrinology 147 (2006) 1140-1147.

[144] C.K.Song, L .W.Enquist, T .J.Bartness, New developments in tracing neural circuits with herpesviruses, Virus Res. 111 (2005) 235-249.

[145] A.Pocai, S.Obici, G.J.Schwartz, L.Rossetti, A brain-liver circuit regulates glucose homeostasis, Cell Metab 1 (2005) 53-61.

[146] L.W.Swanson, P .E.Sawchenko, Hypothalamic integration: organization of the paraventricular and supraoptic nuclei, Annu. Rev. Neurosci. 6 (1983) 269-324.

[147] C.Broberger, T.Hökfelt, Hypothalamic and vagal neuropeptide circuitries regulating food intake, Physiol. Behav. 74 (2001) 669-682.

[148] M.Bamshad, V.T.Aoki, M .G.Adkison, W .S.Warren, T .J.Bartness, Central nervous system origins of the sympathetic nervous system outflow to white adipose tissue, Am. J. Physiol. 275 (1998) R291-9.

[149] R.M.Buijs, S .E.la Fleur, J.Wortel, C.Van Heyningen, L.Zuiddam, T .C.Mettenleiter, A.Kalsbeek, K.Nagai, A.Niijima, The suprachiasmatic nucleus balances sympathetic and parasympathetic output to peripheral organs through separate preautonomic neurons, J. Comp. Neurol. 464 (2003) 36-48.

[150] C.Yi, S.E.La Fleur, E.Fliers, A.Kalsbeek, The role of the autonomic nervous liver innervation in the control of energy metabolism, Biochim. Biophys. Acta 1802 (2010) 416431.

[151] S.Moreno, S.Farioli-Vecchioli, M.P.Cerù, Immunolocalization of peroxisome proliferator-activated receptors and retinoid x receptors in the adult rat cns, Neuroscience 123 (2004) 131-145.

[152] A.L.Bookout, Y.Jeong, M.Downes, R .T.Yu, R .M.Evans, D .J.Mangelsdorf, Anatomical profiling of nuclear receptor expression reveals a hierarchical transcriptional network, Cell 126 (2006) 789-799.

[153] F.Gofflot, N.Chartoire, L.Vasseur, S.Heikkinen, D.Dembele, J.Le Merrer, J.Auwerx, Systematic gene expression mapping clusters nuclear receptors according to their function in the brain, Cell 131 (2007) 405-418.

[154] T.A.Roepke, Oestrogen modulates hypothalamic control of energy homeostasis through multiple mechanisms, J. Neuroendocrinol. 21 (2009) 141-150. 
[155] N.M.Martin, K .L.Smith, S .R.Bloom, C .J.Small, Interactions between the melanocortin system and the hypothalamo-pituitary-thyroid axis, Peptides 27 (2006) 333-339. [156] J.G.Tasker, Rapid glucocorticoid actions in the hypothalamus as a mechanism of homeostatic integration, Obesity (Silver Spring) 14 Suppl 5 (2006) 259S-265S.

[157] M.T.Heneka, G .E.Landreth, Ppars in the brain, Biochim. Biophys. Acta 1771 (2007) $1031-1045$.

[158] L.Cristiano, A.Cimini, S.Moreno, A .M.Ragnelli, M.Paola Cerù, Peroxisome proliferator-activated receptors (ppars) and related transcription factors in differentiating astrocyte cultures, Neuroscience 131 (2005) 577-587.

[159] C.Knauf, J.Rieusset, M.Foretz, P .D.Cani, M.Uldry, M.Hosokawa, E.Martinez, M.Bringart, A.Waget, S.Kersten, B.Desvergne, S.Gremlich, W.Wahli, J.Seydoux, N .M.Delzenne, B.Thorens, R.Burcelin, Peroxisome proliferator-activated receptor-alpha-null mice have increased white adipose tissue glucose utilization, glut4, and fat mass: role in liver and brain, Endocrinology 147 (2006) 4067-4078.

[160] M.V.Chakravarthy, Y.Zhu, M.López, L.Yin, D .F.Wozniak, T.Coleman, Z.Hu, M.Wolfgang, A.Vidal-Puig, M .D.Lane, C .F.Semenkovich, Brain fatty acid synthase activates pparalpha to maintain energy homeostasis, J. Clin. Invest. 117 (2007) 2539-2552.

[161] D.A.Sarruf, F.Yu, H .T.Nguyen, D .L.Williams, R .L.Printz, K .D.Niswender, M .W.Schwartz, Expression of peroxisome proliferator-activated receptor-gamma in key neuronal subsets regulating glucose metabolism and energy homeostasis, Endocrinology 150 (2009) 707-712.

[162] R.G.Parton, J .F.Hancock, Lipid rafts and plasma membrane microorganization: insights from ras, Trends Cell Biol. 14 (2004) 141-147.

[163] M.G.Martin, S.Perga, L.Trovò, A.Rasola, P.Holm, T.Rantamäki, T.Harkany, E.Castrén, F.Chiara, C .G.Dotti, Cholesterol loss enhances trkb signaling in hippocampal neurons aging in vitro, Mol. Biol. Cell 19 (2008) 2101-2112.

[164] K.Simons, D.Toomre, Lipid rafts and signal transduction, Nat. Rev. Mol. Cell Biol. 1 (2000) 31-39.

[165] J.M.Dietschy, S .D.Turley, Cholesterol metabolism in the brain, Curr. Opin. Lipidol. 12 (2001) 105-112.

[166] E.E.Benarroch, Brain cholesterol metabolism and neurologic disease, Neurology 71 (2008) 1368-1373.

[167] G.Cao, K.R.Bales, R .B.DeMattos, S .M.Paul, Liver x receptor-mediated gene regulation and cholesterol homeostasis in brain: relevance to alzheimer's disease therapeutics, Curr Alzheimer Res 4 (2007) 179-184.

[168] K.Abildayeva, P.J.Jansen, V.Hirsch-Reinshagen, V .W.Bloks, A .H .F.Bakker, F.C.S.Ramaekers, J.de Vente, A .K.Groen, C .L.Wellington, F.Kuipers, M.Mulder, 24(s)hydroxycholesterol participates in a liver $\mathrm{x}$ receptor-controlled pathway in astrocytes that regulates apolipoprotein e-mediated cholesterol efflux, J. Biol. Chem. 281 (2006) 1279912808.

[169] D.Perez-Tilve, S.M.Hofmann, J.Basford, R.Nogueiras, P .T.Pfluger, J .T.Patterson, E.Grant, H .E.Wilson-Perez, N .A.Granholm, M.Arnold, J .L.Trevaskis, A .A.Butler, W .S.Davidson, S .C.Woods, S .C.Benoit, M .W.Sleeman, R .D.DiMarchi, D .Y.Hui, M .H.Tschöp, Melanocortin signaling in the cns directly regulates circulating cholesterol, Nat. Neurosci. 13 (2010) 877-882.

[170] N.Preitner, F.Damiola, L.Lopez-Molina, J.Zakany, D.Duboule, U.Albrecht, U.Schibler, The orphan nuclear receptor rev-erbalpha controls circadian transcription within the positive limb of the mammalian circadian oscillator, Cell 110 (2002) 251-260. 


\section{Legends}

\section{Figure 1: Anatomic circuits involved in energy homeostasis}

Schematic representation of the hypothalamic circadian (purple) and energy (blue) networks and their link with the ANS (grey). Overlaps are indicated in mixed purple/blue color. The master clock of the circadian network is SCN. The key structure of the energy network which integrates adiposity (leptin and insulin) and nutrient-related signals (glucose, fatty acids) from the periphery is the ARC. Both networks are indirectly connected through the DMH and the LHA which are both sensitive towards nutritional and circadian information. The NTS receives satiety signals from peripheral organs by vagal afferences and is innervated by the PVN and the LHA, hence receiving input from the hypothalamic circadian and energy networks. The PVN exhibits also other neuroendocrine projections. Some hypothalamic nuclei express MC4R and/or neuropeptide POMC, being part of the melanocortin system. AgRP, agouti-gene related protein; ANS, autonomic nervous system; ARC, arcuate nucleus; $C A R T$, cocaine- and amphetamine related transcript; $C R H$, corticotropin-releasing hormone; $D M H$, dorsomedial hypothalamus; DMV, dorsal motor nucleus of the vagus nerve; LHA, lateral hypothalamic area; $M C 4 R$, melanocortin receptor 4; $M n P O$, median preoptic nucleus; MPOA, median preoptic area; MCH, melanin concentrating hormone; NPY, neuropeptide Y; NTS, nucleus tractus solitarius; POMC, pro-opiomelanocortin; PVN, paraventricular nucleus; SCN, suprachiasmatic nucleus; sPVZ, subparaventricular zone; TRH, thyrotrophinreleasing hormone; VLPO, ventrolateral preoptic nucleus.

\section{Figure 2: Integration of adiposity signals in POMC and AgRP neurons.}

The adiposity signals leptin and insulin both increase the expression of POMC in POMC neurons (A) and decrease the expression of AgRP in AgRP neurons (B), respectively. In both POMC and AgRP neurons, leptin binding to its receptor leads to the recruitment of JAK2, and the subsequent phosphorylation of STAT3. Phosphorylated STAT3 translocates into the nucleus where it either activates POMC or inhibits AgRP transcription dependent on the type of neuron. The binding of insulin to its receptor triggers a phosphorylation cascade mediated by IRS resulting in the activation of PI3K/Akt. Phosphorylated Akt enters the nucleus and phosphorylates FOXO1, which is present on the promoter of POMC and AgRP, thereby diminishing POMC and activating AgRP expression. The inactivation of FOXO1 by phosphorylation leads to its exclusion from the nucleus and the subsequent increase of POMC and repression of AgRP transcription. In addition to insulin, leptin can also induce the PI3K/Akt cascade. In POMC neurons, the insulin- or leptin-mediated generation of $\mathrm{PIP}_{3}$ further leads to an opening of $\mathrm{K}_{\mathrm{ATP}}$ channels and the consecutive cell hyperpolarization. AgRP, agouti-gene related protein; IRS, insulin receptor substrate; JAK2, janus kinase 2; $K_{A T P}$, ATP-dependent potassium channel; PI3K, phosphatidyl inositol 3 kinase; PIP2, phosphatidyl inositol 2 phosphate; PIP3, phosphatidyl inositol 3 phosphate; POMC, proopiomelanocortin; STAT3, signal transducer and activator of transcription 3.

\section{Figure 3: Hypothalamic glucose sensing.}

In response to an increase of extracellular nutrient levels such as glucose, the ATP/ADP ratio raises leading to different consequences depending on the neurochemical phenotype of the neuron. In glucose excited neurons (1), the increased ATP/ADP ratio induces the closure of $\mathrm{K}^{+}{ }_{\text {ATP }}$ channels and thus cell depolarization leading to $\mathrm{Ca}^{2+}$ entry through voltage-gated channels. Finally, intracellular $\mathrm{Ca}^{2+}$ increases neuronal activity. In inhibited neurons (2), glucose induces hyperpolarization by several mechanisms (such as ATP-induced $\mathrm{Na}^{+} / \mathrm{K}^{+}-$ $\mathrm{ATP}_{\text {ase }}, \mathrm{K}^{+}$-ATPase and $\mathrm{Cl}^{-}$channel activation). 
GLUT, glucose transporter; $K_{A T P}$, ATP-dependent potassium channel; TCA cycle, tricarboxylic acid cycle.

Figure 4: Hypothalamic fatty acid sensing and cross-talk whith hypothalamic glucose sensing.

After uptake into the cell, fatty acids are esterified and enter either lipid biosynthesis or $\beta$ oxidation after translocation into mitochondria via CPT1. Mitochondrial oxidation of LCFACoA is controlled by the avaibility of malonyl-CoA, a potent CPT1-inhibitor. Malonyl-CoA is produced from acetyl-CoA, end product of the Krebs cycle which is fed by glucose as well as fatty acid oxidation, and thereby the cellular sensor of carbohydrate and lipid availability. The formation of malonyl-CoA is catalyzed by ACC, which is inhibited by AMPK, itself inhibited by glucose. Malonyl-CoA accumulation ACC activation or AMPK as well as CPT1 inhibition induces a decrease in food intake.

ACC, acetyl-CoA carboxylase; AMPK, AMP-activated protein kinase; CPT1, carnithine palmitoyl transferase; FAS, fatty acid synthase; GLUT, glucose transporter; LCFA, long chain fatty acid; TCA cycle, tricarboxylic acid cycle. 


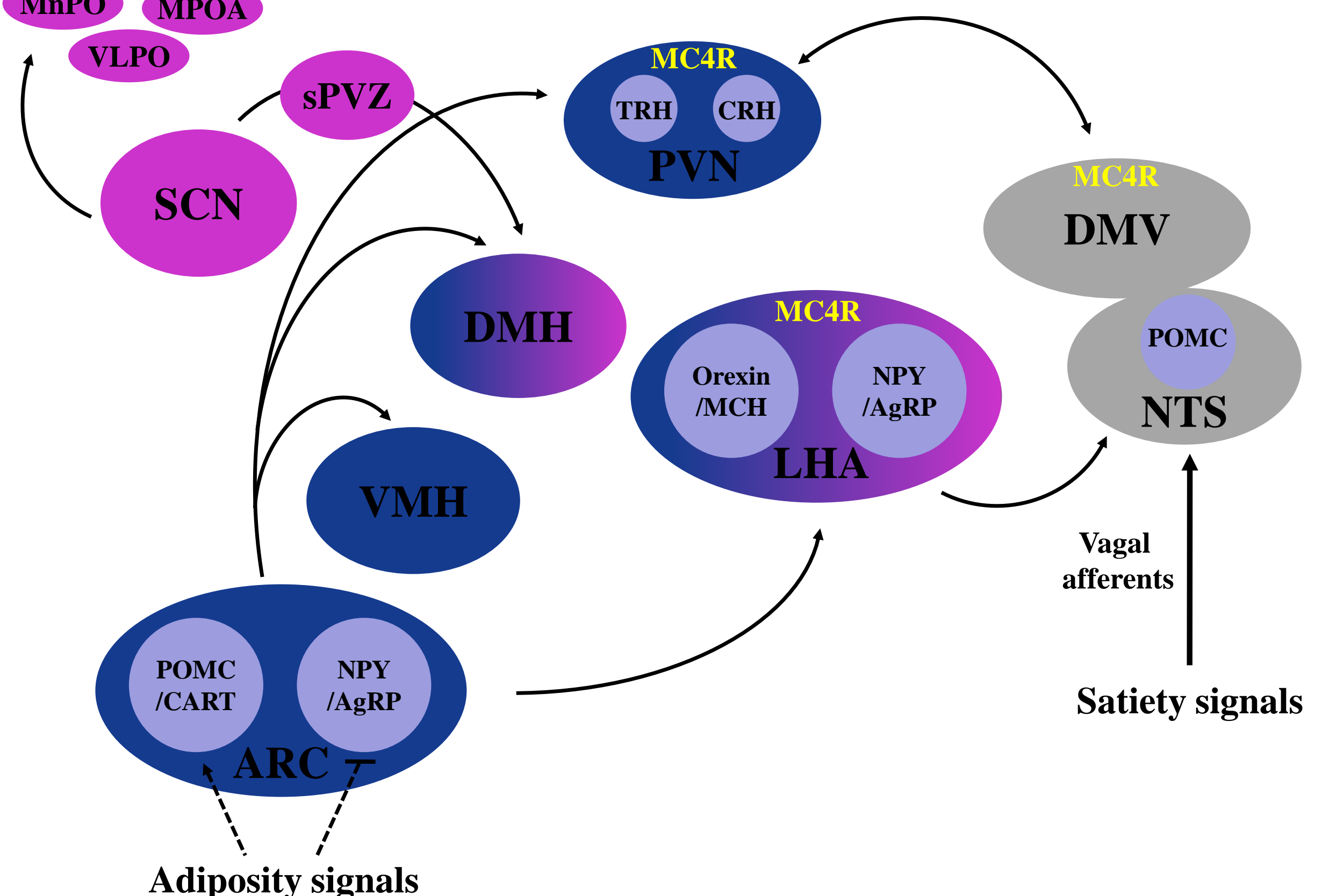

Adiposity signals

Nutrient related signals

Figure 1 


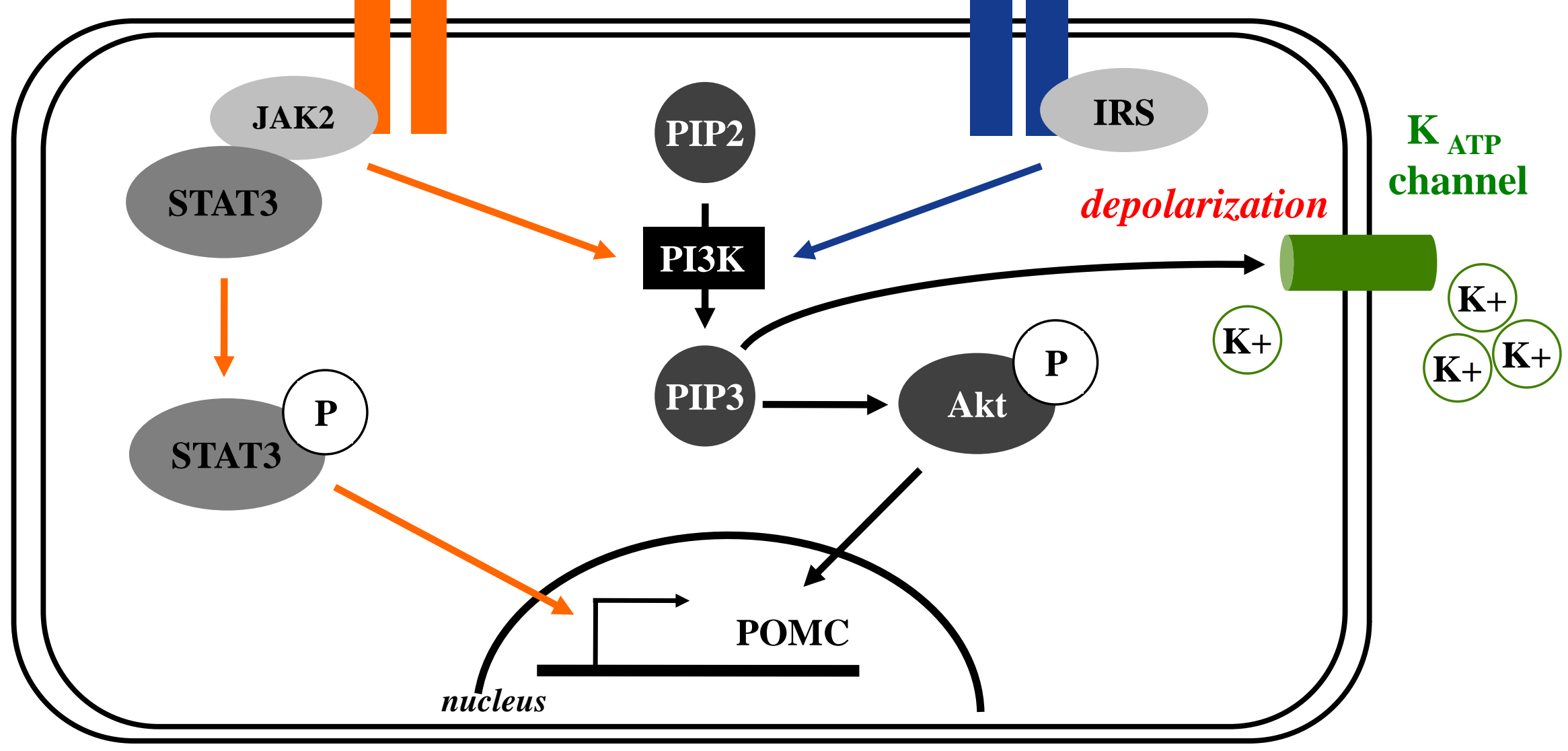

POMC neuron 


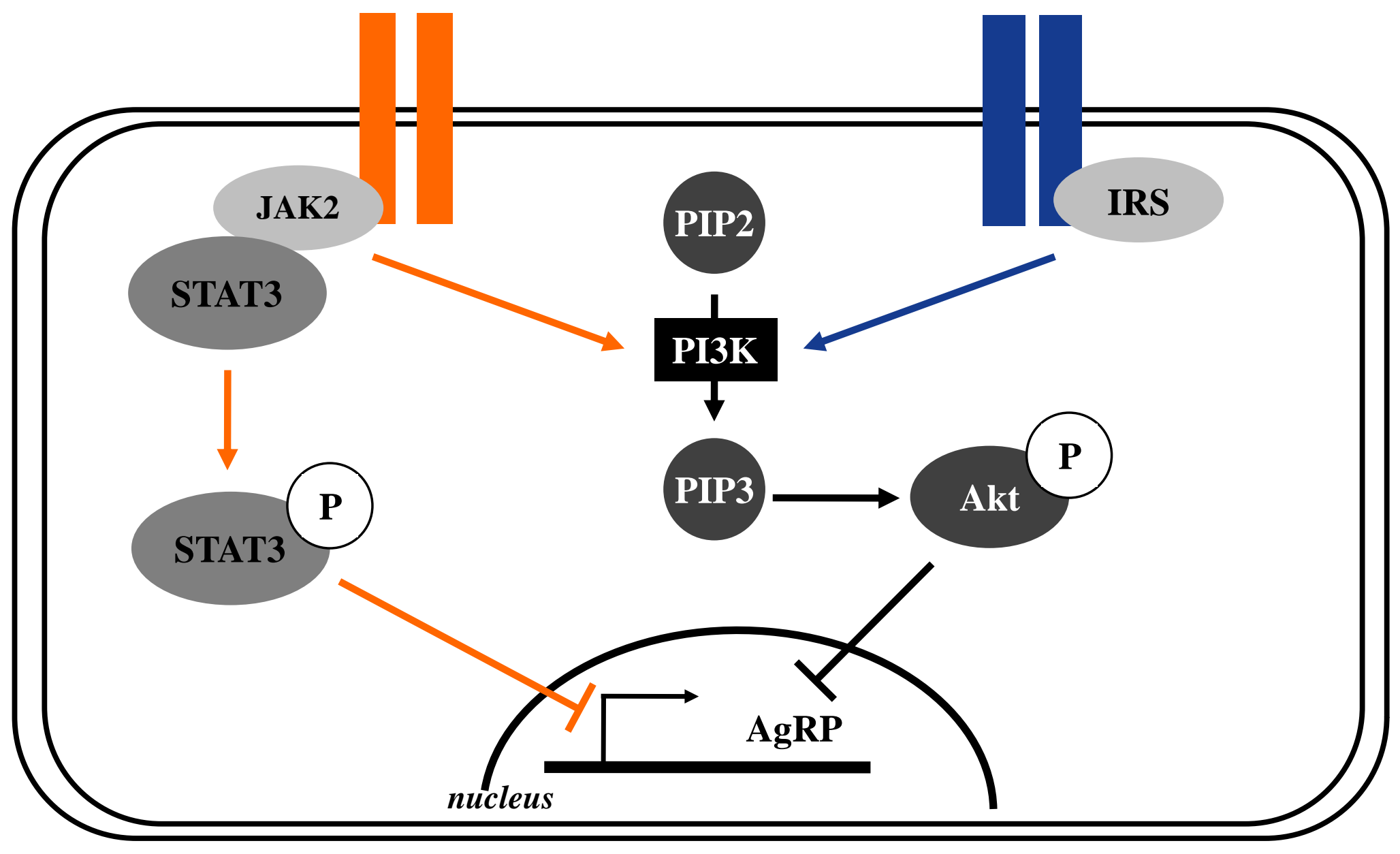

AgRP neuron

:̊: INSULIN 


\section{GLUCOSE b GLUT2}

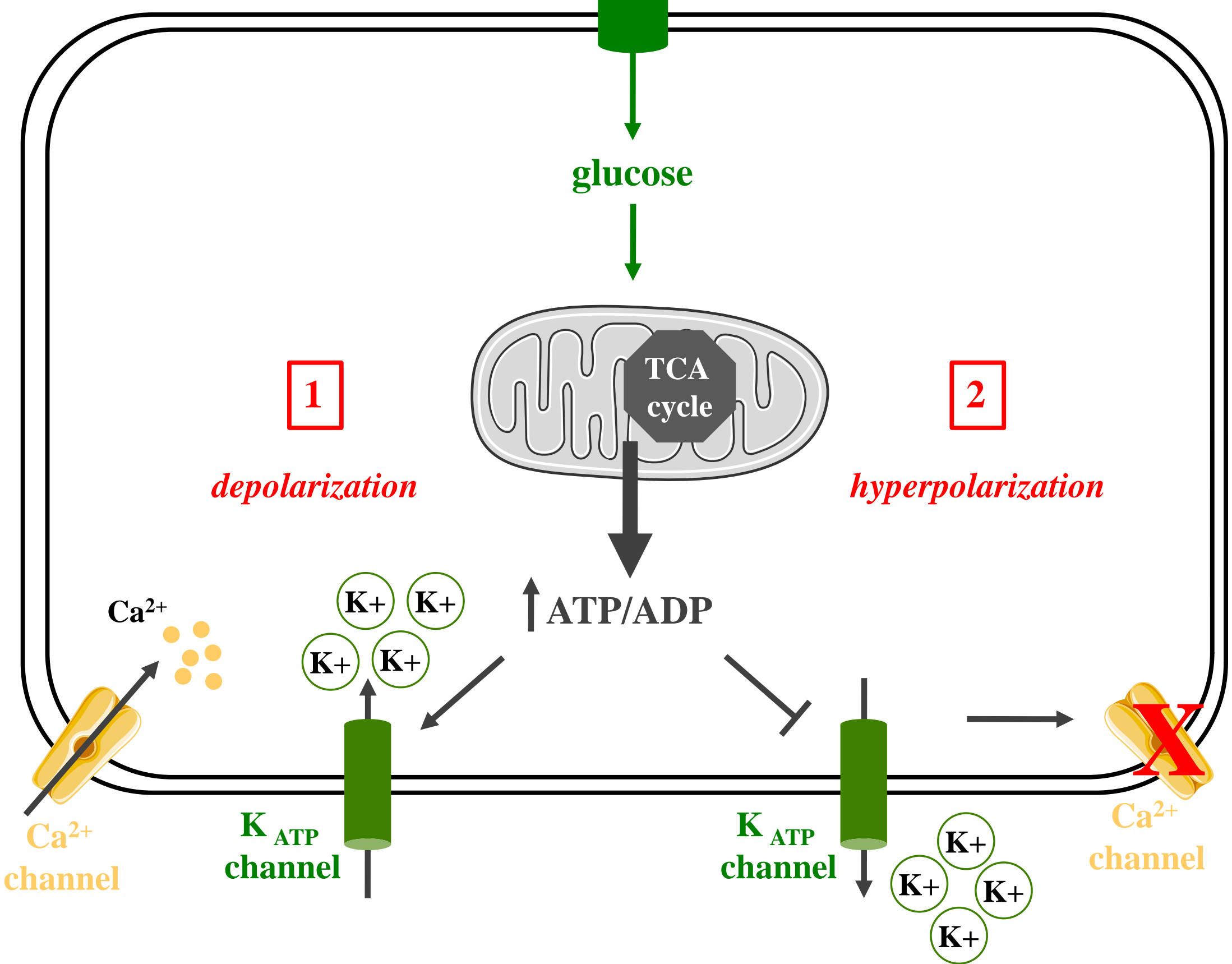




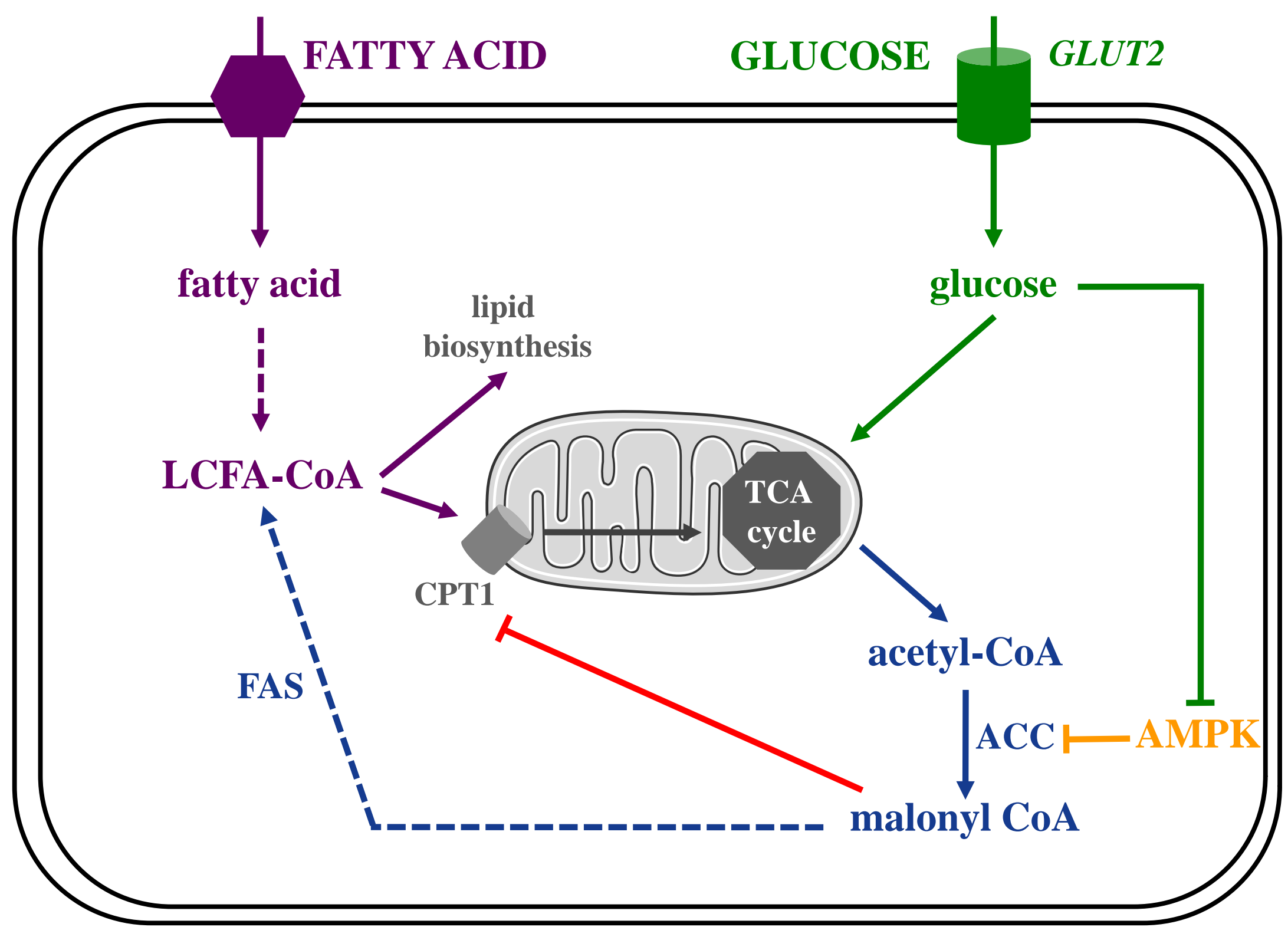

